University of South Carolina

Scholar Commons

10-1997

\title{
Evaluation of Special Sensor Microwave/Imager Satellite Data for Regional Soil Moisture Estimation over the Red River Basin
}

\author{
Venkataraman Lakshmi \\ Eric F. Wood \\ Bhaskar J. Choudhury
}

Follow this and additional works at: https://scholarcommons.sc.edu/geol_facpub

Part of the Earth Sciences Commons

\section{Publication Info}

Published in Journal of Applied Meteorology, Volume 36, Issue 10, 1997, pages 1309-1328. Lakshmi, V., Wood, E. F., \& Choudhury, B. J. (1997). Evaluation of special sensor microwave/imager satellite data for regional soil Moisture Estimation over the Red River Basin. Journal of Applied Meteorology, 36 (10) 1309-1328.

This Article is brought to you by the Earth, Ocean and Environment, School of the at Scholar Commons. It has been accepted for inclusion in Faculty Publications by an authorized administrator of Scholar Commons. For more information, please contact digres@mailbox.sc.edu. 


\title{
Evaluation of Special Sensor Microwave/Imager Satellite Data for Regional Soil Moisture Estimation over the Red River Basin
}

\author{
Venkataraman Lakshmi,* Eric F. Wood, and Bhaskar J. Choudhury ${ }^{+}$ \\ Water Resources Program Department of Civil Engineering and Operations Research, \\ Princeton University, Princeton, New Jersey
}

(Manuscript received 14 August 1996, in final form 8 January 1997)

\begin{abstract}
Regional-scale estimation of soil moisture using in situ field observations is not possible due to problems with the representativeness of the sampling and costs. Remotely sensed satellite data are helpful in this regard. Here, the simulations of 19 - and $37-\mathrm{GHz}$ vertical and horizontal polarization brightness temperatures and estimation of soil moistures using data from the Special Sensor Microwave/Imager (SSM/I) for $7980.25^{\circ} \times 0.25^{\circ}$ boxes in the southwestern plains region of the United States for the time period between 1 August 1987 and 31 July 1988 are presented. A coupled land-canopy-atmosphere model is used for simulating the brightness temperatures. The land-surface hydrology is modeled using a thin-layer hydrologic model. The canopy scattering is modeled using a radiative transfer model, and the atmospheric attenuation is characterized using an empirical model. The simulated brightness temperatures are compared with those observed by the SSM/I sensor aboard the Defense Metereological Satellite Program satellite. The observed brightness temperatures are used to derive the soil moistures using the canopy radiative transfer and atmospheric attenuation model. The discrepancies between the SSM/I-based estimates and the simulated soil moisture are discussed. The mean monthly soil moistures estimated using the $19-\mathrm{GHz} \mathrm{SSM} / \mathrm{I}$ brightness temperature data are interpreted along with the mean monthly leaf area index and accumulated rainfall. The soil moistures estimated using the 19-GHz SSM/I data are used in conjunction with the hydrologic model to estimate cumulative monthly evaporation. The results of the simulations hold promise for the utilization of microwave brightness temperatures in hydrologic modeling for soil moisture estimation.
\end{abstract}

\section{Introduction}

Soil moisture is an important hydrologic variable in a variety of land-surface-atmosphere interactions. It is the response of the land surface to atmospheric forcing and controls the partitioning of rainfall into runoff and infiltration. Soil moisture affects (along with the surface temperature) the depth of the planetary boundary layer, circulation-wind patterns (Mahfouf et al. 1987; Lanicci et al. 1987; Zhang et al. 1982), and regional water and energy budgets. The study of global climate using global climate models (GCMs) has shown that soil moisture is a very important factor (Walker et al. 1977; Rowntree et al. 1983; Rind 1982; Mintz 1984). Evapotranspiration plays an im-

\footnotetext{
* Current affiliation: General Sciences Corporation, Laboratory for Atmospheres, NASA/Goddard Space Flight Center, Greenbelt, Maryland.

${ }^{+}$Current affiliation: Hydrological Sciences Branch, NASA/Goddard Space Flight Center, Greenbelt, Maryland.

Corresponding author address: Dr. Venkataraman Lakshmi, General Sciences Corporation, Laboratory for Atmospheres, NASA/Goddard Space Flight Center, Greenbelt, MD 20771.

E-mail: venkat@spectra.gsfc.nasa.gov
}

portant role in determining surface temperatures, surface pressure, rainfall, and motion (Shukla et al. 1982). Evapotranspiration in turn depends on soil moisture (together with incoming radiation and a host of other meteorological factors). Soil moisture is very closely connected to hydrology and climate (Yeh et al. 1984) and is important in agricultural applications. Simulated soil moisture can be compared to observations to determine the validity of the parameterizations used in modeling.

Projects like the Global Energy and Water Experiment Continental Scale International Project involve the development and testing of hydrologic models on a continental scale over the southern plains of the United States. The availability of datasets for the validation of continentalscale soil moisture would be very useful. Remote sensing methods have an advantage over in situ observations because they sample the variability and offer repeated temporal coverage. In addition, in situ observations are expensive and may result in biases depending on the heterogeneity of variations and the spatial sampling interval.

The microwave frequencies of the electromagnetic spectrum are the most sensitive to the variations of soil moisture (Schmugge 1985) due to the polar nature of water. Here, the choice of which passive microwave remote sensing system to use was dictated by the availability of only 
the Special Sensor Microwave/Imager (SSM/I), a microwave sensor with global spatial and daily temporal coverage (dependent on latitude). In addition, the SSM/I is a very stable, sensitive, and well-calibrated sensor (Hollinger et al. 1990), which makes it a very appealing choice. The SSM/I frequencies are affected by both soil moisture and vegetation. An increased vegetation amount results in decreased sensitivity of the SSM/I to soil moisture as the soil moisture signal gets modulated by the vegetation cover (Choudhury et al. 1990).

The data from the SSM/I have been used for various land-surface, ocean-surface, and atmospheric characteristics determination. The quantities derived from SSM/I include oceanic total precipitable water (Alihouse et al. 1990a), cloud liquid water content (Alihouse et al. 1990b), ocean-surface wind speed (Goodberlet et al. 1990), land-surface temperature (McFarland et al. 1990), atmospheric water vapor over oceans (Schluessel and Emery 1990), sea ice classification (Steffen and Schweiger 1990), and snow mapping (Nagler and Rott 1992). Rainfall over oceans has been estimated using the 37-GHz brightness temperature measurements of the SSM/I and the Scanning Multichannel Microwave Radiometer (SMMR) (Prabhakara et al. 1992a,b). Reflectivities derived from the $19-$ and $37-\mathrm{GHz}$ observed brightness temperatures show a good correlation with the seasonal cycle of biomass growth (Choudhury 1993). The influence of soil moisture on SSM/I brightness temperatures has been recognized in studies involving the effect of rainfall on SSM/I radiances. Heymsfield and Fulton (1992), Teng et al. (1993), and Choudhury and Golus (1988) have used the concept of antecedent precipitation index (API) as a measure of the soil wetness (Saxton et al. 1967; Choudhury et al. 1983) to develop a regression relation between soil wetness and brightness temperatures. The brightness temperature has been related to API for the 6.6-GHz SMMR data (Choudhury and Golus 1988) and the 19-GHz SSM/I data (Teng et al. 1993). The work of Teng et al. (1995) follows a series of works (Choudhury et al. 1987; Becker and Choudhury 1988; Townshend 1989) in investigating the dependence of the $37-\mathrm{GHz}$ microwave polarization difference index (the difference between the vertical and horizontal polarization brightness temperatures) on vegetation and soil moisture.

Previous work involving large-scale hydrologic modeling using microwave satellite data has either been at a very coarse resolution (i.e., SMMR data) or has had simplified hydrologic parameterizations (API substituted for actual soil moisture). The surface soil moisture has been derived using the $6.6-\mathrm{GHz}$ (resolution $150 \mathrm{~km}$ ) frequency passive microwave data over a $150-\mathrm{km}$ area from the SMMR (Owe et al. 1992) and, when compared to weekly field measurements for a period of $3 \mathrm{yr}$, showed good agreement. Simplified hydrologic models using API as a surrogate for soil moisture and regression techniques have been used (Teng et al. 1993), along with the 19- and 37-GHz SSM/I brightness temperature data for the Midwest region and 6.6-GHz SMMR data for the Southern Great Plains region (Choudhury and Golus 1988) in order to estimate soil moisture. The present work attempts to improve the previous methods by using the 19- and 37-GHz data, which are at a higher resolution (compared to the 6.6-GHz data), along with a physically based hydrologic modeling framework that solves for the complete water and energy budgets and computes the soil moisture instead of using the API representation. The estimation of soil moisture is carried out by using a radiative transfer model for the vegetation canopy (Choudhury et al. 1990) and an atmospheric attenuation model (Choudhury 1993).

This study is the final step in our aim to utilize the SSM/I microwave brightness temperature data for regional soil moisture estimation. The coupled thin-layer hydrology-canopy radiative transfer and atmospheric attenuation model has been tested, and sensitivity analyses have been undertaken (Lakshmi 1995; Lakshmi et al. 1996a). The role of heterogeneities in vegetation and soil characteristics has been investigated (Lakshmi et al. 1996b). The results of the heterogeneity analysis (Lakshmi 1995; Lakshmi et al. 1996b) have shown that heterogeneities in rainfall and vegetation (and hence soil moisture) do not affect the retrieval process.

\section{Coupled land-canopy-atmosphere model}

A thin-layer model of soil hydrology is coupled to the canopy radiative transfer model through the soil moisture and the surface temperature, which serve as the boundary conditions for the canopy radiative transfer process. The atmospheric attenuation model deals with the attenuation due to atmospheric water vapor and oxygen. A more complete description may be found in Lakshmi (1995) and Lakshmi et al. (1996a).

\section{a. Thin-layer soil hydrologic model}

This section describes the thin-layer hydrologic model. The model is divided into two layers - the top layer is $1 \mathrm{~cm}$ thick, and the bottom layer is $99 \mathrm{~cm}$ thick (these are fixed). The model includes the following processes: infiltration of rainfall, runoff, bare soil evaporation from the top layer, exchange fluxes between the top layer and the bottom layer, subsurface drainage from the bottom layer, and transpiration by vegetation from the bottom layer. The water balance for the two soil layers $(1.0-\mathrm{cm}$ top-layer thickness) and the top canopy interception storage are given by

$$
\begin{aligned}
\frac{d C}{d t} & =P-P_{n}, \\
z_{1} \frac{d \theta_{1}}{\partial t} & =P_{n}-E-R-q_{1,2},
\end{aligned}
$$

and

$$
z_{2} \frac{d \theta_{2}}{\partial t}=q_{1,2}-q_{2}-T-Q_{b},
$$


where $C(0 \leq C \leq S)$ is the amount of intercepted water on the canopy, $S$ being the canopy storage capacity; the units for $S$ and $C$ are in millimeters; $\theta_{1}\left(\theta_{r} \leq \theta_{1} \leq \theta_{s}\right)$ and $\theta_{2}\left(\theta_{r} \leq \theta_{2} \leq \theta_{s}\right)$ are the volumetric soil moistures of layer 1 (with thickness $z_{1}$ and layer 2 (with thickness $\left.z_{2}\right) ; q_{1,2}$ and $q_{2}$ are the exchange fluxes from layer 1 to layer 2 and drainage from layer 2; roots are present in the bottom layer and extract moisture for transpiration from layer 2 only; $T$ is the transpiration assumed to come out of layer 2 only; $R$ is the runoff; and $P_{n}$ is the net precipitation reaching the soil surface, which is given by $P_{n}=P-S_{a}$ if $P \geq S_{a}$, where $P$ is the precipitation, and $P_{n}=0$ if $P<S_{a}$, where $S_{a}$ is the available storage in the canopy given by $S_{a}=S-C$. The water table is assumed to lie below the bottom layer, and the dynamics of the water table are not modeled. Also, the capillary rise from the water table is not considered. Since the object of this study is to simulate the top 1-cm-layer soil moisture, it is assumed that the changes in the depth of the water table do not affect the top layer soil moisture. However, when the water table is close to the surface (such as an area adjacent to a stream channel), this assumption will break down. The model is not being used at a fine spatial resolution to simulate the soil moistures close to stream channels; it is used for a catchment in an average sense. The initial conditions for the above set of differential equations are given by $C(t=0)=$ $C^{0}, \theta_{1}(t=0)=\theta_{1}^{0}$, and $\theta_{2}(t=0)=\theta_{2}^{0}$. The choice of a $1-\mathrm{cm}$ top layer depth is dictated by the fact that the penetration depth of microwave radiation can be taken as being on the order of one-tenth of the wavelength to a wavelength (Ulaby et al. 1986). Therefore, for the $19-\mathrm{GHz}$ frequency, this would be 0.1 to $1.5 \mathrm{~cm}$ and 0.08 to $0.8 \mathrm{~cm}$ for the $37-\mathrm{GHz}$ frequency.

\section{b. Radiative transfer model}

The radiative transfer model for the vegetation canopy is a part of the coupled soil-canopy-atmosphere model used in the brightness temperature simulations as well as in the sensitivity studies examining the role of heterogeneities on brightness temperatures. The canopy radiative transfer model described in this section follows the description of Choudhury et al. (1990). The landsurface hydrologic model (described above) computes the soil moisture and surface temperature of a $1-\mathrm{cm}$ layer, which serve as the bottom boundary conditions for the canopy radiative transfer model. The microwave radiation originating from the soil surface is modulated by the overlying vegetation canopy, resulting in the canopy-top brightness temperature values. This canopy-top brightness temperature (microwave radiation) is attenuated by the atmospheric water vapor before it reaches the satellite sensor. The radiative transfer model treats the interaction of microwave radiation from the soil with the vegetation branches, stems, and leaves. The model is analytic and provides an expression for the canopytop brightness temperature using the two-point Gaussian quadrature, which results in a system of two coupled ordinary differential equations, with the bottom boundary condition dictated by the soil moisture and surface temperature and the top boundary condition dependent on the radiation from the sky incident on the canopy.

The canopy-top brightness temperature $T_{B}(\gamma, p)$ is related to the at-satellite brightness temperature $T_{B}(A$, $\gamma, p$ ) for zenith angle $\gamma$ of the sensor, polarization $p$ (horizontal or vertical), and $A$ (the altitude of the radiometer) by

$$
T_{B}(A, \gamma, p)=\tau_{a}(A, \gamma) T_{B}(\gamma, p)+T_{\text {atm }}(A, \gamma),
$$

where $\tau_{a}(A, \gamma)$ is the transmissivity of the atmosphere and $T_{\text {atm }}(A, \gamma)$ is the radiation entering the radiometer from the atmosphere.

The canopy-top brightness temperature $T_{B}(\gamma, p)$ will be derived, followed by the derivation and discussion of $\tau_{a}(A, \gamma)$ and $T_{\text {atm }}(A, \gamma)$. The radiative transfer equation is given by Choudhury et al. (1990) and Stephens et al. (1988) as

$$
\begin{aligned}
\mu \frac{d I(x, \mu)}{d x}=k(\mu)\{ & -I(x, \mu)+\frac{\omega(\mu)}{2} \\
& \times \int_{-1}^{1} P\left(\mu, \mu^{\prime}\right) I\left(x, \mu^{\prime}\right) d \mu^{\prime} \\
& \left.+[1-\omega(\mu)] T_{0}\right\}
\end{aligned}
$$

where $I(x, \mu)$ is the radiance at depth $x$ within the canopy (the top of the canopy is taken to be $x=0$, and the bottom of the canopy is taken to be $x=1$ ) at an angle whose cosine is $\mu[\mu=\cos (\gamma), \mu>0$ for radiation direction toward soil, and $\mu<0$ for radiation direction away from soil], $k(\mu)$ is the extinction coefficient, $\omega(\mu)$ is the single scattering albedo, $P\left(\mu, \mu^{\prime}\right)$ is the phase function (the probability that the element will scatter incident radiation at $\mu^{\prime}$ to direction $\mu$ ), and $T_{0}$ is the soil-canopy temperature.

The boundary conditions are given by

$$
I(0, \mu)=T_{\text {sky }}
$$

and

$$
I(1,-\mu)=R(\mu) I(1, \mu)+[1-R(\mu)] T_{0},
$$

where $T_{\text {sky }}$ is the intensity of atmospheric radiation incident on the top of the canopy and $R(\mu)$ is the reflectivity of the soil. The first condition states that the downwelling radiation at the top of the canopy is the sky radiation, and the second condition states that the upwelling radiation at the bottom of the canopy equals the emissivity of the soil plus the incident radiation reflected at the soil surface. The canopy-top brightness temperature is given by

$$
T_{B}(\gamma, p)=I(0,-\mu)
$$

The above differential equation is solved using the 
two-point Gaussian quadrature (Chandrashekar 1960) to yield the brightness temperatures. The brightness temperature is given by a linear combination of $T_{\text {sky }}$ and $T_{0}$ as

$$
T_{B}(\gamma, p)=A T_{\text {sky }}+(1-A) T_{0},
$$

where $A$ is defined as the effective reflectivity of the soil-canopy system (Choudhury et al. 1990). The polarization difference index is defined as the difference between the horizontally polarized and the vertically polarized reflectivity of the soil-canopy system (Lakshmi 1995). For details regarding the derivation of the brightness temperatures, the reader is referred to Choudhury et al. (1990) or Lakshmi (1995). The polarization difference index is a better estimate of soil moisture than the polarization difference of brightness temperatures since it does not depend on surface temperature, air temperature, or precipitable water used to compute satellite brightness temperature.

This microwave radiation is then attenuated by the atmospheric water vapor before it reaches the satellite. The atmospheric effects are accounted for using the method developed by Choudhury (1993).

The canopy-top brightness temperatures undergo atmospheric attenuation due to atmospheric oxygen and water vapor before resulting in the at-satellite brightness temperatures $\left[T_{B}(A, \gamma, p)\right]$. The optical thickness, which is computed based on the total precipitable water vapor in the atmospheric column $V(\mathrm{~mm})$ (Choudhury 1993), is related to the atmospheric transmissivity $\tau_{a}$. The effective radiating temperature of the atmosphere is related to the air temperature $T_{a}$ and the total precipitable water. The total precipitable water and the effective radiating temperature are used to compute the sky temperature $T_{\text {sky }}$, which serves as the upper boundary condition on the canopy. The at-satellite brightness temperatures $\left[T_{B}(A, \gamma, p)\right]$ are computed using the canopytop brightness temperatures $\left[T_{B}(\gamma, p)\right]$ for polarization $p$ (horizontal or vertical), altitude $A$, atmospheric attenuation $\tau_{a}(A, \gamma)$, and atmospheric radiation entering the radiometer $T_{\text {atm }}(A, \gamma)$ (approximated to be equal to $T_{\text {sky }}$ ) (Ulaby et al. 1981) as

$$
T_{B}(A, \gamma, p)=\tau_{a}(A, \gamma) T_{B}(\gamma, p)+T_{\text {sky }} .
$$

The average $\left(\bar{T}_{B}\right)$ and polarization difference $(\Delta T)$ brightness temperature are defined as

$$
\bar{T}_{B}=\frac{1}{2}\left[T_{B}(A, \gamma, V)+T_{B}(A, \gamma, H)\right]
$$

and

$$
\Delta T=T_{B}(A, \gamma, V)-T_{B}(A, \gamma, H) .
$$

A more complete description of the canopy radiative transfer model and the atmospheric attenuation model is given in Choudhury et al. (1990) and Choudhury (1993), respectively. The reader is also referred to Lakshmi (1995) for details.
TABLE 1. Parameters for the coupled soil-canopy-atmosphere model.

\begin{tabular}{ll}
\hline \hline \multicolumn{1}{c}{ Parameter } & \multicolumn{1}{c}{ Value } \\
\hline Albedo (soil) $\alpha_{s}$ & 0.15 \\
Albedo (vegetation) $\alpha_{v}$ & 0.20 \\
Emissivity (soil) $\epsilon_{s}$ & 1.00 \\
Emissivity (vegetation) $\epsilon_{v}$ & 1.00 \\
Roughness length (soil) $z_{0, s}$ & $0.001 \mathrm{~m}$ \\
Roughness length (vegetation) $z_{0, s}$ & $0.07 \mathrm{~m}$ \\
Zero plane displacement (soil) $d_{s}$ & 0.0 \\
Zero plane displacement (vegetation) $d_{v}$ & $0.25 \mathrm{~m}$ \\
Top-layer thickness $z_{1}$ & $0.01 \mathrm{~m}$ \\
Bottom-layer thickness $z_{2}$ & $0.99 \mathrm{~m}$ \\
Leaf area index $L$ & Biweekly LAIs \\
Minimum stomatal resistance $r_{\min }^{\text {st }}$ & $100 \mathrm{~s} \mathrm{\textrm {m } ^ { - 1 }}$ \\
Transpiration parameter $\Lambda$ & 0.5 \\
Porosity $\theta_{s}$ & 0.50 \\
Residual soil moisture $\theta_{r}$ & 0.02 \\
Brooks-Corey parameter $m$ & 0.2 \\
Air entry suction head $\psi_{c}$ & $0.2 \mathrm{~m}$ \\
Saturated hydraulic conductivity $K_{s}$ & $1.89 \times 10^{-6} \mathrm{~m} \mathrm{~s}^{-1}$ \\
Transition soil moisture $\theta^{*}$ & 0.12 \\
Wilting soil moisture $($ volumetric $) \theta_{w}$ & 0.05 \\
Base flow parameter $Q_{b}^{\text {max }}$ & $3.38 \mathrm{~mm} \mathrm{~h} \mathrm{~h}^{-1}$ \\
Base flow parameter $\theta_{b}^{*}$ & 0.15 \\
Base flow parameter $Q_{b}^{*}$ & $0.06 \mathrm{~mm} \mathrm{day}{ }^{-1}$ \\
& Hourly data, Surface \\
Meteorological data & Airways stations \\
& Hourly data, \\
Rainfall data & MDR data \\
Oven dry thickness of leaf $d_{0}$ & $0.1 \mathrm{~mm}$ \\
& Radiosonde data \\
Precipitable water & $($ derived) \\
\hline
\end{tabular}

\section{Data and methods}

A summary of the SSM/I microwave brightness temperature data, in situ ground observations, derived datasets, and the parameters used in this study is presented in the following sections, as well as tabulated in Table 1 (parameters for the coupled land-canopy-atmosphere model).

\section{a. Special Sensor Microwave/Imager}

The SSM/I provides a measure of the brightness temperature at four frequencies $(19.4,22.2,37.0$, and 85.5 $\mathrm{GHz}$ ) and two polarizations (horizontal and vertical) for each of the four frequencies (except for $22.2 \mathrm{GHz}$, which has only vertical polarization). The SSM/I data used here were obtained by the Defense Meteorological Satellite Program spacecraft satellite $F 8$ at an altitude of $833 \mathrm{~km}$ with an orbit period of $102 \mathrm{~min}$, an inclination of $98.8^{\circ}$, and an equatorial crossing of 0613 LT during the ascending orbit. The swath width of the sensor is $1400 \mathrm{~km}$, and the zenith angle is $53.1^{\circ}$. The beam resolution is approximately $12.5 \mathrm{~km}$ in the along-track and cross-track directions. The resolution of the sensor varies with frequency. The footprint size is about $56 \mathrm{~km}$ at $19 \mathrm{GHz}$ and $33 \mathrm{~km}$ at $37 \mathrm{GHz}$. The data were gridded on a $0.25^{\circ} \times 0.25^{\circ}$ grid and used for comparing the simulated values. The ascending orbit of the SSM/I was 
TABLE 2. List of Surface Airways stations.

\begin{tabular}{clrrr}
\hline \hline & & \multicolumn{1}{c}{ Latitude } & Longitude & $\begin{array}{c}\text { Height } \\
(\mathrm{ft})\end{array}$ \\
No. & \multicolumn{1}{c}{ Name } & $32^{\circ} 25^{\prime}$ & $99^{\circ} 41^{\prime}$ & 21 \\
\hline 1 & Abilene, TX & $35^{\circ} 4^{\prime}$ & $101^{\circ} 42^{\prime}$ & 23 \\
2 & Amarillo, TX & $32^{\circ} 54^{\prime}$ & $97^{\circ} 02^{\prime}$ & 22 \\
3 & Dallas-Fort Worth, TX & $33^{\circ} 39^{\prime}$ & $101^{\circ} 49^{\prime}$ & 25 \\
4 & Lubbock, TX & $31^{\circ} 57^{\prime}$ & $102^{\circ} 11^{\prime}$ & 22 \\
5 & Midland, TX & $35^{\circ} 24^{\prime}$ & $97^{\circ} 36^{\prime}$ & 20 \\
6 & Oklahoma City, OK & $33^{\circ} 18^{\prime}$ & $104^{\circ} 32^{\prime}$ & 20 \\
7 & Roswell, NM & $32^{\circ} 13^{\prime}$ & $98^{\circ} 11^{\prime}$ & 20 \\
8 & Stephenville, TX & $33^{\circ} 58^{\prime}$ & $98^{\circ} 29^{\prime}$ & 21 \\
9 & Wichita Falls, TX & $32^{\circ} 21^{\prime}$ & $94^{\circ} 39^{\prime}$ & 22 \\
10 & Longview, TX & $35^{\circ} 11^{\prime}$ & $103^{\circ} 36^{\prime}$ & 22 \\
11 & Tucumcari, NM & $31^{\circ} 22^{\prime}$ & $100^{\circ} 30^{\prime}$ & 20 \\
12 & San Angelo-Mathis, TX & $36^{\circ} 27^{\prime}$ & $103^{\circ} 09^{\prime}$ & 33 \\
13 & Clayton, NM & $35^{\circ} 20^{\prime}$ & $94^{\circ} 22^{\prime}$ & 23 \\
14 & Fort Smith, AR & $37^{\circ} 46^{\prime}$ & $99^{\circ} 58^{\prime}$ & 33 \\
15 & Dodge City, KS & $31^{\circ} 48^{\prime}$ & $106^{\circ} 24^{\prime}$ & 32 \\
16 & El Paso, TX & $31^{\circ} 14^{\prime}$ & $94^{\circ} 45^{\prime}$ & 22 \\
17 & Lufkin-Angelina, TX & & & \\
\hline
\end{tabular}

used because, during this time, the land-surface conditions are relatively homogeneous and the analysis and interpretation of the SSM/I data are easier. The data used were from the period between 1 August 1987 and 31 July 1988. There are missing days_all of December 1987, the first 12 days of January 1988, a day in October 1987, and 3 days in May 1988. The SSM/I overheated and was turned off from 1 December 1987 to 12 January 1988. There are some missing days over individual pixels due to the precession of the orbits. The standard error of the determination of the absolute calibration of $\mathrm{SSM} / \mathrm{I}$ is $\pm 3 \mathrm{~K}$ (Hollinger et al. 1990). This has been determined from comparisons using the SSM/I aboard an aircraft and flying it over ocean, forest, and desert areas. The 22.2-GHz data do not contain horizontal polarization. Since our algorithms rely heavily on the polarization difference brightness temperatures (due to its sensitivity to soil moisture), we could not use the 22.2$\mathrm{GHz}$ data. The $85.5-\mathrm{GHz}$ data were not used due to its extreme sensitivity to cloud liquid droplets and ice particles in the atmosphere. The radiative transfer equations would have to be considerably changed in order to account for the scattering of the $85.5-\mathrm{GHz}$ radiation. Hence, it was decided that only the 19 - and the $37-\mathrm{GHz}$ data would be used.

\section{b. Datasets}

The meteorological data were obtained from the surface airways data (17 stations on a hourly basis) from EarthInfo's NCDC (National Climate Data Center) data product. The variables used here from that database are hourly air temperature, dewpoint temperature, air pressure, wind speed, cloud height (defined as the height of the lowest sky cover layer more than one-half opaque), total sky cover, and wind speed. Table 2 gives a list of the surface airways stations, as well as their geographic location. The incoming longwave radiation is given by
$I_{l}=K E_{a} \sigma T_{a}^{4}$, where $K$ is a factor that accounts for cloud cover effects and is given by $K=1+0.17 N^{2}$ (Tennessee Valley Authority 1972), $N$ is the fraction of the sky covered by clouds, $E_{a}$ is the atmospheric emissivity given by (Idso 1981) $E_{a}=0.740+0.0049 e, e$ is the vapor pressure in millibars, $\sigma$ is the Stefan-Boltzmann constant $\left(5.67 \times 10^{-8} \mathrm{~J} \mathrm{~m}^{-2} \mathrm{~s}^{-1} \mathrm{~K}^{-4}\right)$, and $T_{a}$ is the surface air temperature. The Image Processing Workbench (Dozier and Frew 1990) is used to generate incoming clear-sky shortwave radiation based on the digital elevation map of the area. This value is corrected for cloud cover effects (Eagleson 1970) by the factor 1 $-(1-K) N$ to obtain the corrected incoming shortwave radiation $K$ and account for the cloud height ( $K=0.18$ $+0.0853 z$, where $z$ is cloud-base altitude in kilometers).

The vegetation data have been obtained from the University of Maryland reprocessed National Oceanic and Atmospheric Administration (NOAA-GVI) Global Vegetation Index data product (Goward et al. 1994). This NOAA-GVI has been synthesised from measurements made by the Advanced Very High Resolution Radiometer (AVHRR) onboard NOAA polar-orbiting satellites. The data comprises 3 yr (1983, 1987, and 1989) of biweekly composite observations (to minimize the amount of cloud contamination). The observations were mapped to a Plate Carree projection (between $75^{\circ} \mathrm{N}$ and $55^{\circ} \mathrm{S}$, with a resolution of $16 \mathrm{~km}$ at the equator) and calibrated radiometrically for spectral reflectance. The normalized difference vegetation index (NDVI) values were converted to leaf area index (LAI, $L$ ) using a Beer's law kind of variation (Baret and Guyot 1991) as NDVI $=\mathrm{NDVI}_{\infty}+\mathrm{NDVI}_{g}-\mathrm{NDVI}_{\infty} \exp \left(-K_{\mathrm{NDVI}} L\right)$, where $\mathrm{NDVI}_{g}$ corresponds to bare soil (0.193), $\mathrm{NDVI}_{\infty}$ is the asymptotic value when LAI tends to infinity (limit reached when LAI is greater than 8.0), and $K_{\mathrm{NDVI}}$ controls the slope (an extinction coefficient). The values of $K_{\mathrm{NDVI}}$ and $\mathrm{NDVI}_{\infty}$ depend on the average leaf inclination (equal to 0.93 and 0.965 for an average leaf inclination of $50^{\circ}$ ) (Baret and Guyot 1991).

The other vegetation parameters for the simulation used by the canopy radiative transfer model are thickness of the leaf $(0.1 \mathrm{~mm})$, volumetric stem moisture content (0.1), and volumetric branch moisture content $(0.1)$. The simulated brightness temperatures are relatively insensitive to these parameters. The stem to ground area ratio, the branch to stem area ratio, and the volumetric moisture of the leaf play an important role in the estimation of brightness temperature and are estimated as described in a later section.

The manually digitized radar (MDR) is a program that produces a complete computer-generated composite map of the echo characteristics. The MDR data have been generated using information from all the 100 radars around the country (Moore and Smith 1979). The data are presented as video integrator and processor (VIP) levels, which are the maximum levels for that particular grid box. The VIP levels are related to the rainfall rate (echo intensity is a function of precipitation) and MDR 


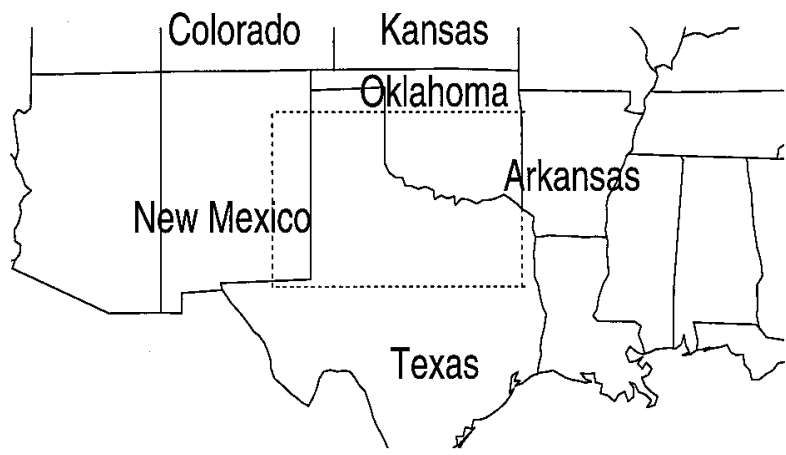

FIG. 1. Location of the study area (denoted by a dotted rectangular box).

VIP levels 1, 2, 3, 4, 5, and 6 correspond to an echo intensity of light, moderate, heavy, very heavy, intense, and extreme, respectively. The VIP levels are converted into rain rates using conversion tables (Fan et al. 1996), which take into account the geographic position of the MDR pixel, the month of the year, and the time of the day. The spatial resolution of the MDR data is $40 \mathrm{~km}$. The data are described in more detail in Baeck and Smith (1994).

The precipitable water content was compiled using the Hydrologic Research Laboratory, National Weather Service radiosonde data for stations in North America for 1972-88 (Bradley and Smith 1993). The original source of this data is from the NCDC. The data were corrected for errors resulting from radiosonde equipment changes, reporting methods for relative humidity data, and degradation of the quality of data due to automation, as well as for the existence of unrealistic superadiabatic layers (Bradley and Smith 1993). The precipitable water was computed for the 0000 UTC radiosonde soundings values corresponding to the study area $\left(31.5^{\circ}\right.$ to $36^{\circ} \mathrm{N}$, and $94.5^{\circ}$ to $\left.104.75^{\circ} \mathrm{W}\right)$ extracted from the North America dataset for each day between $1 \mathrm{Au}-$ gust 1987 and 31 July 1988.

Soil type data for the Red River basin were available (Abdulla et al. 1996). Most of the Red River basin is composed of silt loam and loam soil. The soil for the region outside the Red River basin was considered as a uniform silt loam (in the absence of a distributed dataset). The Brooks-Corey parameters for silt loam soil are $\theta_{r}=0.02, \theta_{s}=0.50, \psi\left(\theta_{s}\right)=0.2 \mathrm{~m}, K_{s}=1.89 \times$ $10^{-6} \mathrm{~m} \mathrm{~s}^{-1}$, and $\mathrm{m}=0.2$ (Rawls et al. 1982).

\section{c. Description of study area}

This study was carried out over an areal extent of $4.75^{\circ}$ in latitude and $10.5^{\circ}$ in longitude in the southwestern plains of the United States (Fig. 1). The study area includes 19 rows and 42 columns of $0.25^{\circ}$ boxes or grid cells of observed SSM/I data. The area includes a small part of eastern New Mexico, most of Oklahoma (except for a small part in the north), and northern Texas (a small portion of the Panhandle is left out). The region has a topographic relief between 600 and $1500 \mathrm{~m}$ in the high plains of eastern New Mexico and western Texas, 300 and $600 \mathrm{~m}$ in the midcontinent plains of north central Texas and central Oklahoma, 150 and $300 \mathrm{~m}$ in eastern Oklahoma, and 0 and $150 \mathrm{~m}$ in the Gulf Atlantic rolling plains of southeastern Texas. The area is made up of gently sloping plains in the eastern Texas and western New Mexico region; irregular plains in the eastern Texas and Oklahoma region and the central part of the study region consist of mostly moderate relief tablelands. The vegetation ranges from grama-buffalo grass in eastern New Mexico and western Texas to mesquite-buffalo grass in south central Texas, from cross timbers in north central Texas to oak hickory pine forests in southeastern Oklahoma and eastern Texas. The land types in the area include subhumid grassland, semiarid grazing land, crop land, irrigated land, crop land pasture, woodland, and forests. The mean annual precipitation ranges from around $40 \mathrm{~cm}$ in the western regions to $120 \mathrm{~cm}$ in the eastern regions of the study area. The eastern part of the study area (eastern Oklahoma and eastern Texas) have many reservoirs: Lake Texoma at the Texas-Oklahoma border, the Garza-Little Elm Reservoir and the the Whitney Reservoir in eastern Texas, and the Eufaula Reservoir in western Oklahoma. The vegetation description above is quantified in the hydrologic model using the LAI and in the canopy radiative transfer model by the stem area index and branch to stem area ratio. The different vegetation types have different stem area indexes and branch to stem area ratios based on the amount of the woody portion.

\section{d. Calibration of parameters and simulation methods}

The coupled soil-canopy-atmosphere model is used to compute the brightness temperatures coinciding with the time of the satellite 0600 LT (equator-crossing time) ascending overpass. The scheme for calibration and validation is outlined in Fig. 2. The spatial resolution of the simulations is the same as that of the GVI dataset, which is approximately $16 \mathrm{~km}$ at the equator. This results in $32 \times 71$ grid cells over the study area $\left(31.5^{\circ}\right.$ to $36^{\circ} \mathrm{N}, 94.5^{\circ}$ to $104.75^{\circ} \mathrm{W}$ ) for the simulations. In the calibration, the coupled soil-canopy-atmosphere model (with soil, radiation, and meteorological inputs; rainfall; and LAI) is used to simulate the soil moisture, the surface temperature, and the $19-\mathrm{GHz}$ polarization difference index for a period of 90 days beginning 1 August 1987. The simulated 19-GHz polarization difference index is later used for parameter estimation. The observed polarization difference index [computed using (6)] corresponding to the observed $19-\mathrm{GHz} \mathrm{SSM} / \mathrm{I}$ brightness temperature data is computed by using the surface temperature (computed using the soil-canopy-atmosphere model above), the precipitable water (derived from radiosonde data), and the air temperature (obtained from the surface airways stations). This observed $19-\mathrm{GHz}$ 


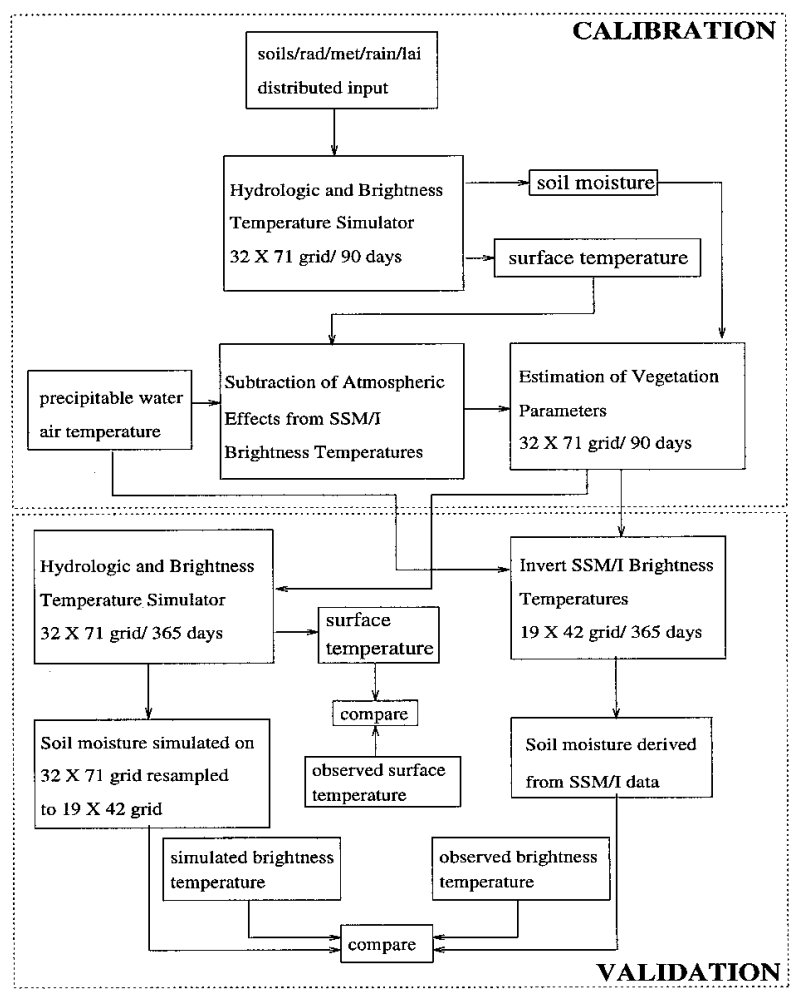

FIG. 2. Scheme for calibration, validation, and comparison of soil moistures and brightness temperatures.

polarization difference index is resampled from the 19 $\times 42$ grid to the simulation grid of $32 \times 71$ grid cells. The parameters (stem area index, the branch to stem area ratio, and the volumetric moisture content of the leaf) are estimated by minimizing the root-mean-square difference between the observed and the simulated 19-GHz polarization difference index over a 90-day period for each of the $32 \times 71$ (simulation grid) cells. These parameters (stem area index and the branch to stem area ratio) are constant over the 1-yr duration. However, the seasonal variability in vegetation comes from the growth and senesence of leaves and the LAI varies as obtained from the AVHRR data (as described in section $3 b$ ). These parameters are used to carry out the simulations for the remainder of the duration from 30 October 1987 to 31 July 1988 on an hourly time step to obtain hourly values of soil moisture and the 19- and $37-\mathrm{GHz}$ brightness temperatures corresponding to the 0600 LT SSM/I ascending overpass. The simulated soil moisture and the 19- and 37-GHz brightness temperatures are resampled to the SSM/I data observation grid-that is, from $32 \times 71$ (approximately $16 \mathrm{~km}$ ) to $19 \times 42\left(0.25^{\circ}\right)$ - for purposes of comparison with the $\mathrm{SSM} / \mathrm{I}$ brightness temperatures and the SSM/I estimated soil moisture. In addition, the simulated surface temperature at $0600 \mathrm{LT}$ during the SSM/I ascending overpass was compared with the minimum air temperature used as a surrogate for the observed surface temperature
(McFarland et al. 1990). The observed SSM/I brightness temperatures are used to derive the polarization difference index for the 19- and 37-GHz frequency by using the atmospheric data and approximating the surface temperature with the observed air temperature since the surface temperature is unknown. The canopy radiative transfer model is used to compute the soil moisture by minimizing the error between the computed and the observed polarization difference index. The soil moisture corresponding to this minimum difference between the simulated and the observed polarization difference index is the SSM/I-estimated soil moisture.

\section{Results and discussion}

\section{a. Errors and correlations on different timescales}

The simulated values of soil moisture, and average and polarization difference brightness temperatures were compared with the SSM/I-derived estimates. The root-mean-squared differences between the simulated and observation-derived quantities were computed on a daily basis (one observation at $0600 \mathrm{LT}$ at the most) and averaged on a weekly and monthly basis for the entire area of $19 \times 42$ grid cells or pixels. The sum of squared difference for each pixel $(i, j)$ is computed over the time steps contained in the entire year $N(i, j)$ :

$$
S\left[X^{\nu}(i, j)\right]=\sum_{k=1}^{N(i, j)}\left[X_{\mathrm{sim}}^{\nu}(i, j, k)-X_{\mathrm{obs}}^{\nu}(i, j, k)\right]^{2},
$$

where $X_{\text {sim }}$ is the simulated and $X_{\mathrm{obs}}$ is the observed quantity $X$ (soil moisture $\theta$, average brightness temperature $\bar{T}_{B}$, and polarization difference brightness temperature $\Delta T_{B}$ ), and $\nu$ is the frequency of the SSM/I (19 or $37 \mathrm{GHz}$ ).

The root-mean-squared difference [for each pixel $(i$, $j)$ ] is determined as

$$
E\left[X^{\nu}(i, j)\right]=\left\{S\left[X^{\nu}(i, j)\right] / N(i, j)\right\}^{1 / 2},
$$

where $N(i, j)$ is the number of the time steps for each pixel $(i, j)$ for which the SSM/I observations are available to compute $X$. The mean and standard deviation (over all pixels) of this root-mean-squared difference $\bar{E}(X)$ and $\sigma_{E}(X)$ are determined. The soil moisture derived from the $19-\mathrm{GHz} \mathrm{SSM} / \mathrm{I}$ observations is different from that derived from the $37-\mathrm{GHz}$ observations. However, both of the observation-derived quantities are compared with the same set of simulated soil moisturesthat is, $\theta_{\text {sim }}^{19}$ and $\theta_{\text {sim }}^{37}$ are the same. In the case of the weekly averaged quantities, $X_{\text {sim }} \nu(i, j)$ and $X_{\text {obs }} \nu(i, j)$ are averaged over a week and a month for the frequency $\nu$ and the pixel location $(i, j)$ before taking the root-meansquared differences. The results of the root-meansquared differences are given in Table 3. As expected, the mean of the root-mean-squared differences decreases as the window of averaging time of the quantities is increased. On the other hand, the standard deviations do not show any consistent trend. The correlation be- 
TABLE 3. Summary of root-mean-squared differences between simulations and observations for $19-$ and $37-\mathrm{GHz}$ brightness temperatures and estimated soil moisture.

\begin{tabular}{|c|c|c|c|c|c|c|}
\hline & \multicolumn{2}{|c|}{ Daily } & \multicolumn{2}{|c|}{ Weekly } & \multicolumn{2}{|c|}{ Monthly } \\
\hline & Mean & Std dev & Mean & Std dev & Mean & Std dev \\
\hline 19-GHz volumetric soil moisture & 0.14 & 0.059 & 0.12 & 0.059 & 0.11 & 0.063 \\
\hline 37-GHz volumetric soil moisture & 0.13 & 0.053 & 0.11 & 0.052 & 0.09 & 0.054 \\
\hline 19-GHz avg brightness temperature $(\mathrm{K})$ & 6.2 & 1.92 & 5.7 & 2.04 & 4.9 & 2.0 \\
\hline 19-GHz polarization difference brightness temperature $(\mathrm{K})$ & 2.6 & 0.84 & 2.2 & 0.83 & 1.8 & 0.82 \\
\hline 37-GHz avg brightness temperature $(\mathrm{K})$ & 5.1 & 1.42 & 4.5 & 1.61 & 3.7 & 1.49 \\
\hline 37-GHz polarization difference brightness temperature $(\mathrm{K})$ & 2.4 & 0.84 & 1.9 & 0.79 & 1.6 & 0.76 \\
\hline
\end{tabular}

tween the simulated and the SSM/I observation-derived soil moistures (Fig. 3) reveals that the monthly averaged values show a correlation coefficient $r$ between 0 and 0.5 (for both the 19- and $37-\mathrm{GHz}$ derived soil moistures). The values range from 0.0 in June 1988 to 0.59 in March 1988 for the $19-\mathrm{GHz}$ derived soil moistures and from 0.17 in August 1987 to 0.59 in March 1988. The variation of $r$ for the monthly averaged case is much smoother than the weekly averaged $r$ variation or the daily $r$ variation as seen in Fig. 3. The $r$ values for the
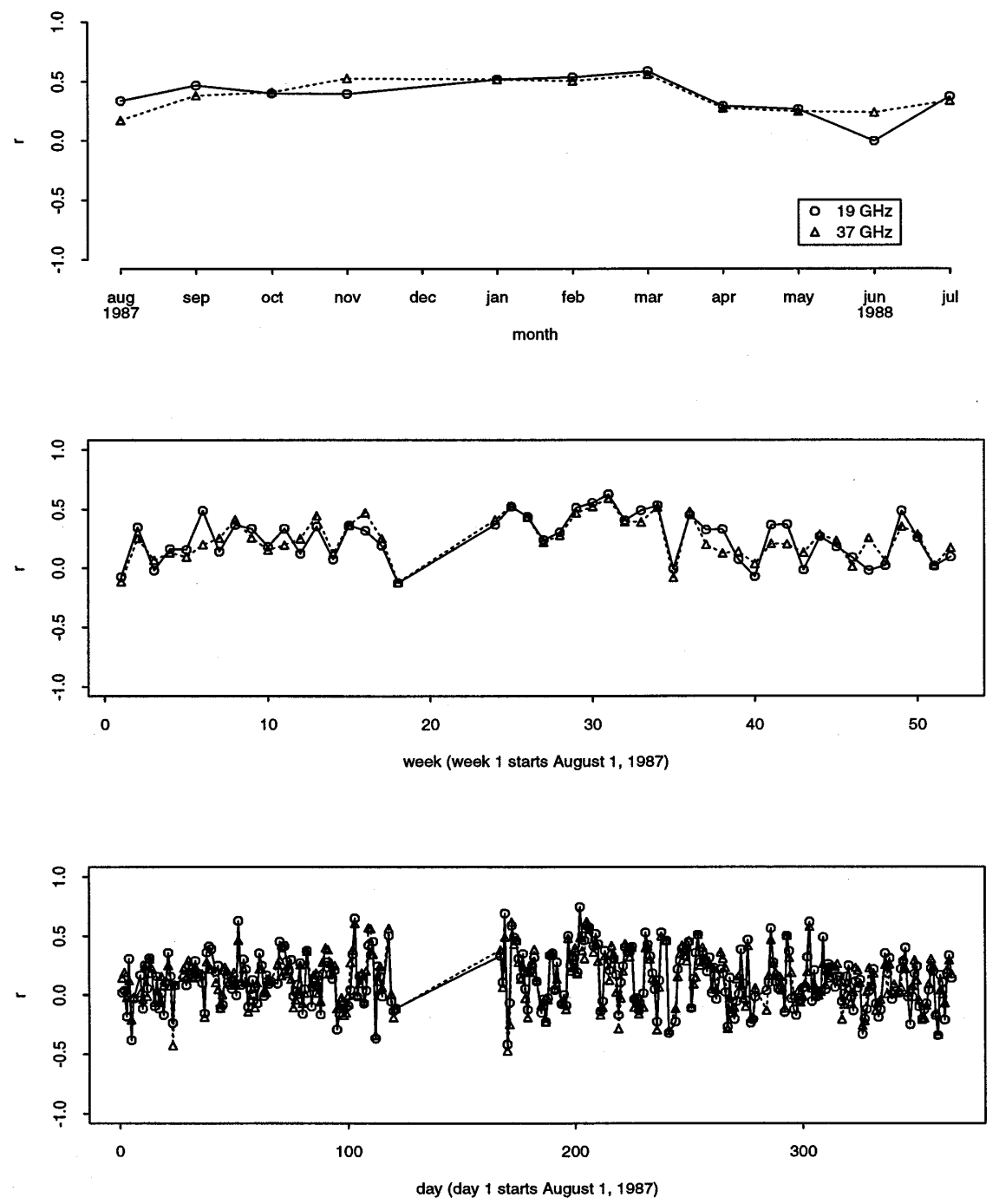

FIG. 3. Correlation coefficient $r$ between the simulated soil moisture and the SSM/I-derived soil moisture using 19 - and $37-\mathrm{GHz}$ brightness temperatures for monthly averaged, weekly averaged, and daily values. 
weekly averaged case vary between -0.1 and 0.63 for the $19-\mathrm{GHz}$ case and between -0.15 and 0.60 for the $37-\mathrm{GHz}$ case. In the case of $r$ based on the daily values, the variations are much larger than the previous two cases and range between -0.4 and 0.75 for the $19-\mathrm{GHz}$ case and between -0.5 and 0.63 for the $37-\mathrm{GHz}$ case. As the time period for the averaging decreases from monthly to daily, the range of fluctuation of the correlation coefficient increases.

The $r$ values in the figures are modest. They represent the level of agreement between the simulated soil moisture and the estimated soil moisture using the SSM/I data. The hydrologic model derives the soil moisture differently than the radiative transfer model that inverts the SSM/I brightness temperatures to obtain soil moistures. These two methods represent different ways of obtaining the same soil moisture. The "best" method would be combining the two methods to obtain a single estimate that combines the characteristics of both the procedures. The hydrologic model relies on our knowledge of soil moisture dynamics and the various inputs that affect the values of soil moistures. The radiative transfer inversion uses the attenuation characteristics of the canopy and the effect of soil moisture on microwave radiation in determining the soil moisture. The combined estimate of soil moisture could be compared to soil moisture observations from large-scale field experiments to determine correlations. The correlations reported above show that the two methods behave in a similar fashion for correlation values greater than 0 . Interpretting the actual numerical values in the statistical sense may not be an appropriate thing to do.

The distribution of root-mean-squared differences for soil moisture is shown in Fig. 4 for the 19- and 37-GHz frequencies. They show results similar to those in Table 3 - that is, as the averaging time frame increases (daily to weekly to monthly averaging). The $37-\mathrm{GHz}$ average brightness temperature has a mean root-mean-squared difference corresponding to daily, weekly, and monthly averaging of $5.1,4.5$, and $3.7 \mathrm{~K}$. The peak frequency of the root-mean-squared differences moves to lesser values of root-mean-squared differences. There is a peak frequency of 0.36 at 0.125 root-mean-squared difference for soil moisture for the daily comparison, versus 0.35 for the peak frequency at 0.075 for the weekly comparison, versus 0.36 for the peak frequency at 0.075 for the monthly comparison for the $19-\mathrm{GHz}$ case. The difference between the weekly and monthly cases is such that there is more mass under the frequency distribution at the lower values of root-mean-squared differences for the monthly averaged case as opposed to the weekly averaged case. This can be seen by comparing the solid lines in the middle and bottom panels in Fig. 4. A similar trend is seen for the $37-\mathrm{GHz}$ frequency case. In the case of the average brightness temperatures (figure not shown), it can be seen that the the peak frequency is 0.28 corresponding to a root-mean-squared difference $6.75 \mathrm{~K}$ for the daily case, the peak frequency is 0.25
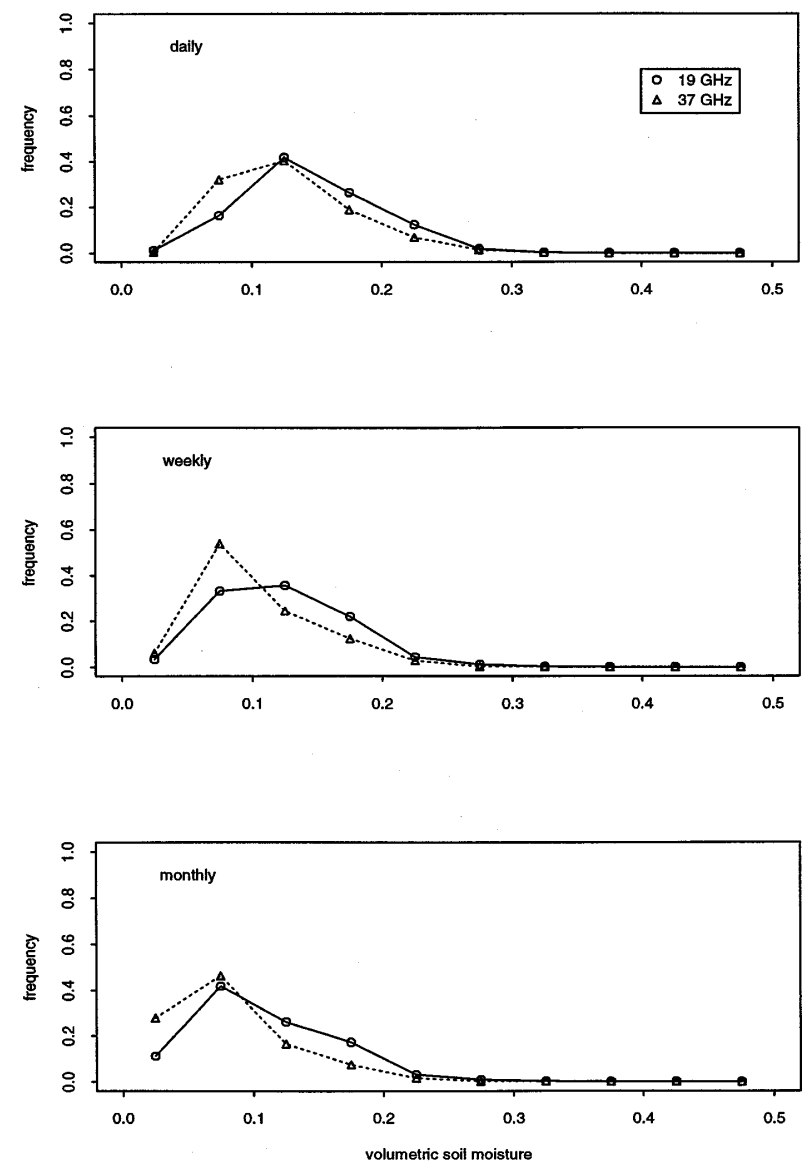

FIG. 4. Frequency distribution of the root-mean-squared difference between the simulated soil moisture and the SSM/I-derived soil moisture using 19- and 37-GHz brightness temperatures for monthly averaged, weekly averaged, and daily values.

corresponding to a root-mean-squared differences of $6.75 \mathrm{~K}$ for the weekly averaging case, and the peak frequency is 0.27 corresponding to a root-mean-squared error of $3.75 \mathrm{~K}$ for the monthly averaged case. The peak frequency may occur at the same location for the daily and weekly cases; however, there is much more mass at the lower values in the weekly averaged case than in the daily case. The monthly averaged case has greater frequencies at lower values than both the weekly and daily cases. The same behavior is seen for the $37-\mathrm{GHz}$ frequency case, as well as for the distribution of the root-mean-squared errors for polarization difference brightness temperature (figure not shown).

The spatial distribution of root-mean-squared differences for the soil moisture (19- and 37-GHz frequencies) is shown as images for the daily case and monthly averaged case in Fig. 5 and Fig. 6, respectively (the weekly case lies in between the daily and monthly). The rootmean-squared differences are highest for the daily case and lowest for the monthly case, with the weekly case falling in between. This is expected from temporal averaging, which smoothes out some of the differences 
$19 \mathrm{GHz}$

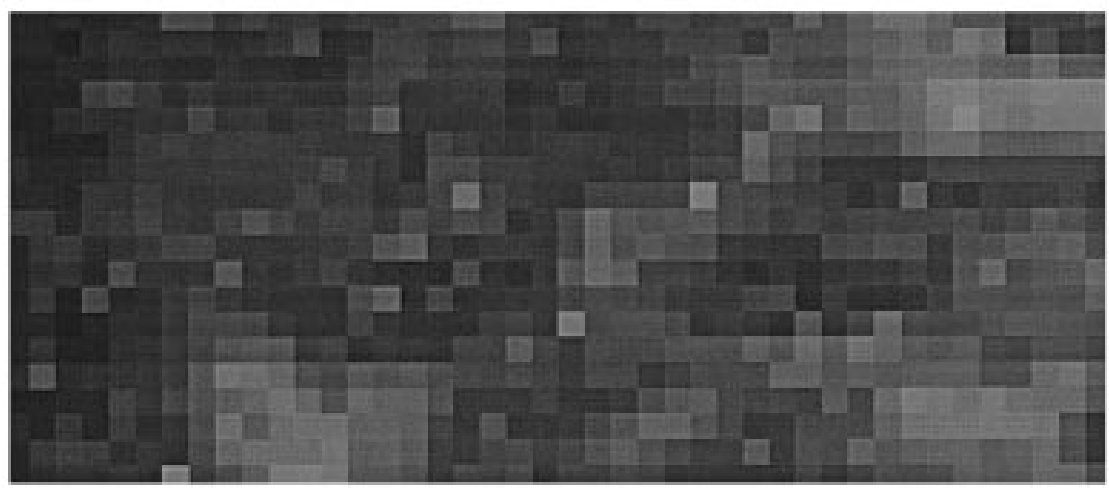

\section{$37 \mathrm{GHz}$}
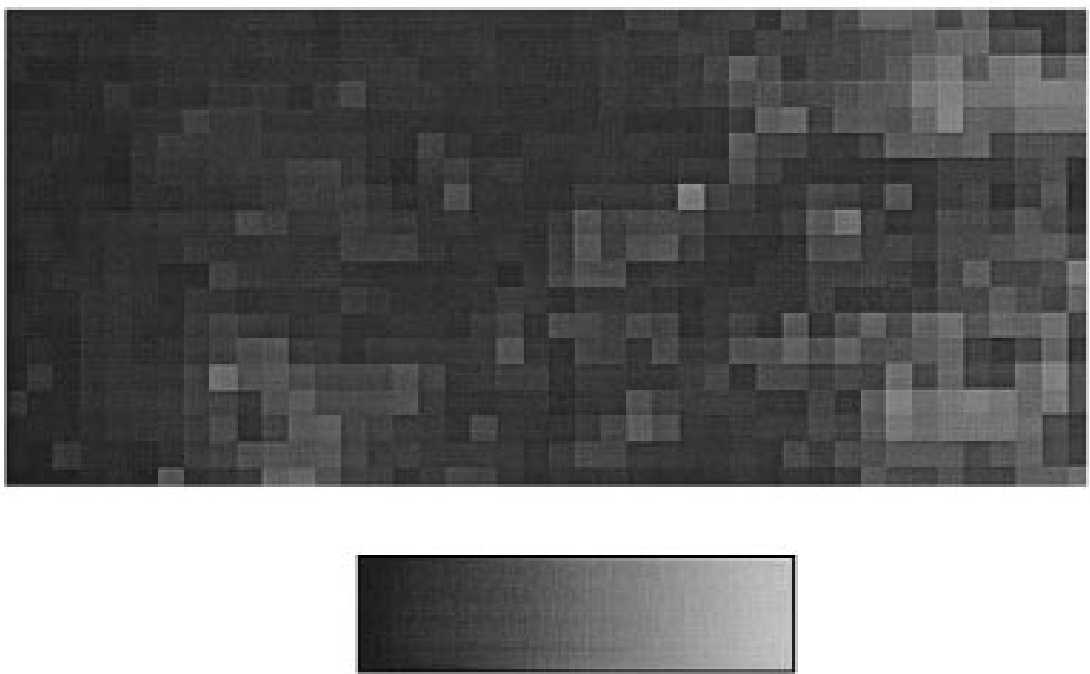

0.0

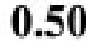

FIG. 5. Root-mean-squared difference between the daily simulated soil moisture and the SSM/Iderived soil moisture using 19- and 37-GHz brightness temperatures.

between the simulated and the SSM/I-estimated values. This is demonstrated in the previous paragraphs in the discussion of correlation coefficients between the simulated and the estimated soil moistures, and the frequency distribution of the root-mean-squared differences between the simulated and the estimated soil moisture.

Figure 7 shows the sensitivity of the SSM/I polarization difference index to LAI (LAI increments are 0.5 in the lower panel) and soil moisture (volumetric soil moisture increments are 0.04 in the upper panel). This figure should be interpreted as sensitivity as well as accuracy. The higher the LAI, the lower the sensitivity of the SSM/I to changes in soil moisture and, hence, the more difficult to detect. This can be used in conjunction with the LAI to arrive at the root-mean-squared errors in Figs. 5 and 6. It can be seen in Fig. 7 that for LAI values of 2 and higher there is virtually no sensi- tivity at $19 \mathrm{GHz}$ of the brightness temperature signal to soil moisture. Hence, under conditions of LAI greater than or equal to 2 , we will have to abandon hope of estimating soil moisture using the 19-GHz SSM/I brightness temperatures. We will have to resort to other methods when attempting to estimate soil moistures in heavily vegetated regions.

The comparison between simulated surface temperature at $0600 \mathrm{LT}$ corresponding to the SSM/I ascending overpass and the minimum air temperature of the day (obtained from Surface Airways station observations), which can be used as a surrogate for the surface temperature (McFarland et al. 1990), shows a root-meansquared difference ranging from 1 to $4 \mathrm{~K}$ (figure not shown). The surface temperature observations can be derived from AVHRR channel 4 and channel 5 measurements. However, the AVHRR equatorial overpass is 0230 LT (descending) and 1430 LT (ascending). These 


\section{$19 \mathrm{GHz}$}

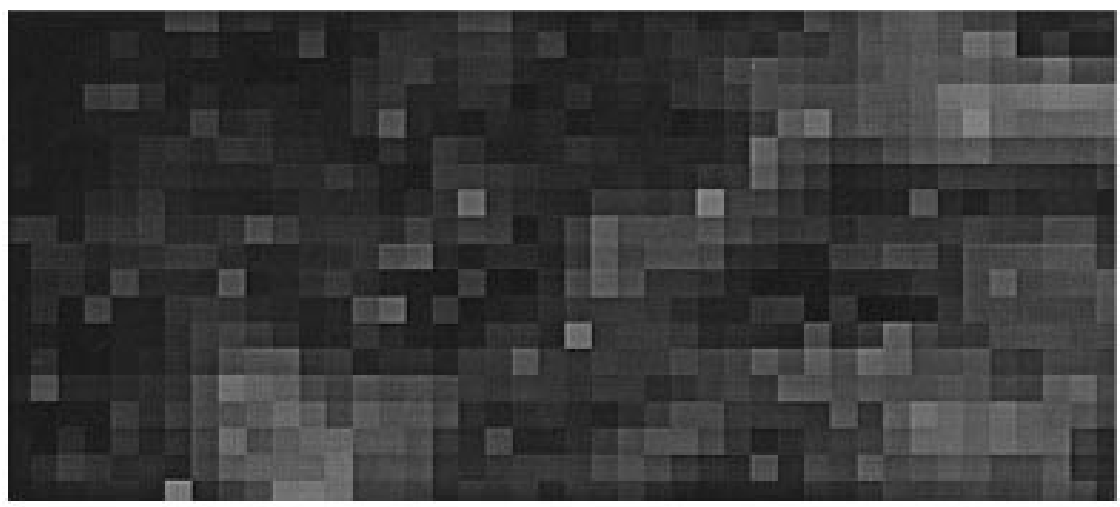

\section{$37 \mathrm{GHz}$}
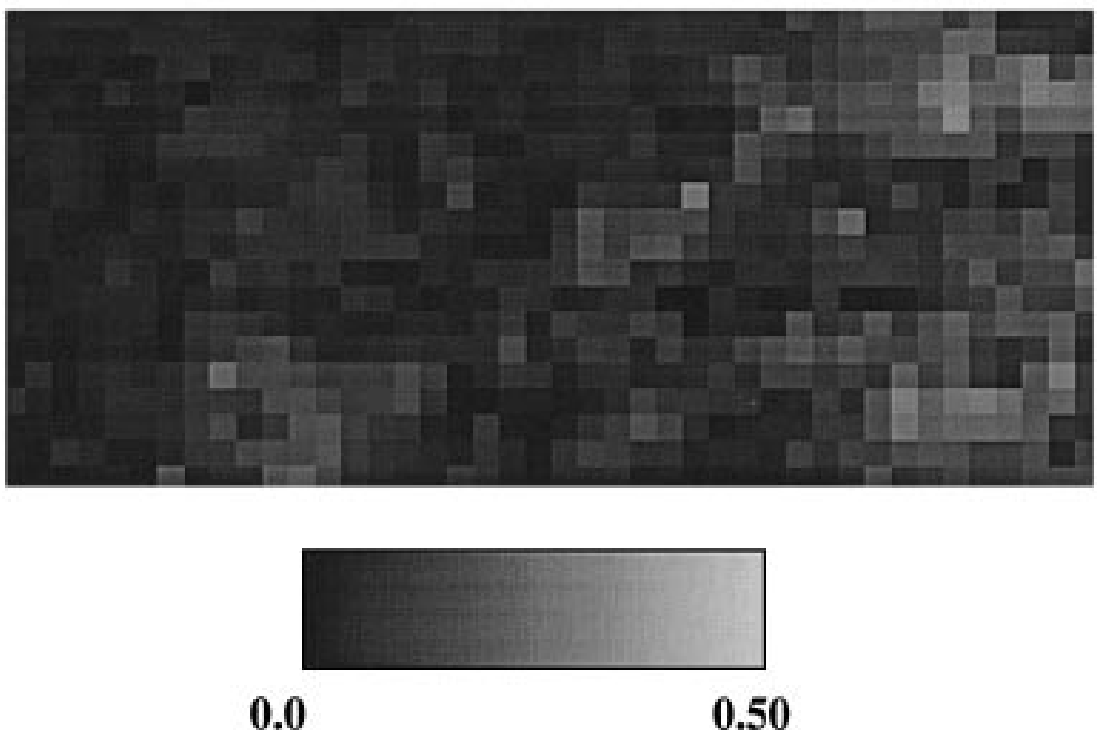

FIG. 6. Root-mean-squared difference between the monthly averaged simulated soil moisture and the SSM/I-derived soil moisture using 19- and 37-GHz brightness temperatures.

times do not coincide with the SSM/I overpass and therefore cannot be used for comparison purposes.

\section{b. Pixel results for soil moisture and brightness temperatures}

The comparison of simulated and SSM/I-estimated soil moisture for individual grid cells or pixels is discussed below. The following discussion intends to describe agreements and disagreements between the two. Figure 8 shows the daily time series of good agreement between simulated and SSM/I-derived soil moisture, and average and polarization difference brightness temperatures for the 19-GHz frequency for a particular pixel, and Fig. 9 shows the same pixel but at the $37-\mathrm{GHz}$ frequency. Good agreement means that root-meansquared volumetric soil moisture differences between hydrologic model-simulated and SSM/I-estimated results are within 5\%; bad-poor agreement is for the $\mathrm{SSM} / \mathrm{I}$ inversion that gives us completely saturated soil moistures, and the hydrologic simulation did not consider either the snow-ice or lake-covered regions. Figure 8 corresponds to a $0.25^{\circ} \times 0.25^{\circ}$ pixel located at $33.0^{\circ} \mathrm{N}, 104.25^{\circ} \mathrm{W}$. The root-mean-squared differences for the soil moisture and the average and polarization difference brightness temperatures are $0.03,6.18$, and $1.71 \mathrm{~K}$, respectively. In Fig. 9, it can be seen that the $37-\mathrm{GHz}$ observed polarization difference temperature is very high (much higher than the simulated value) on day 190 (6 February 1988). The reason for this is the melting of snow, which causes a large increase in polarization difference brightness temperature. The Atmospheric Environment Service of Canada has developed an algorithm to detect melting snow (T. Szeliga 

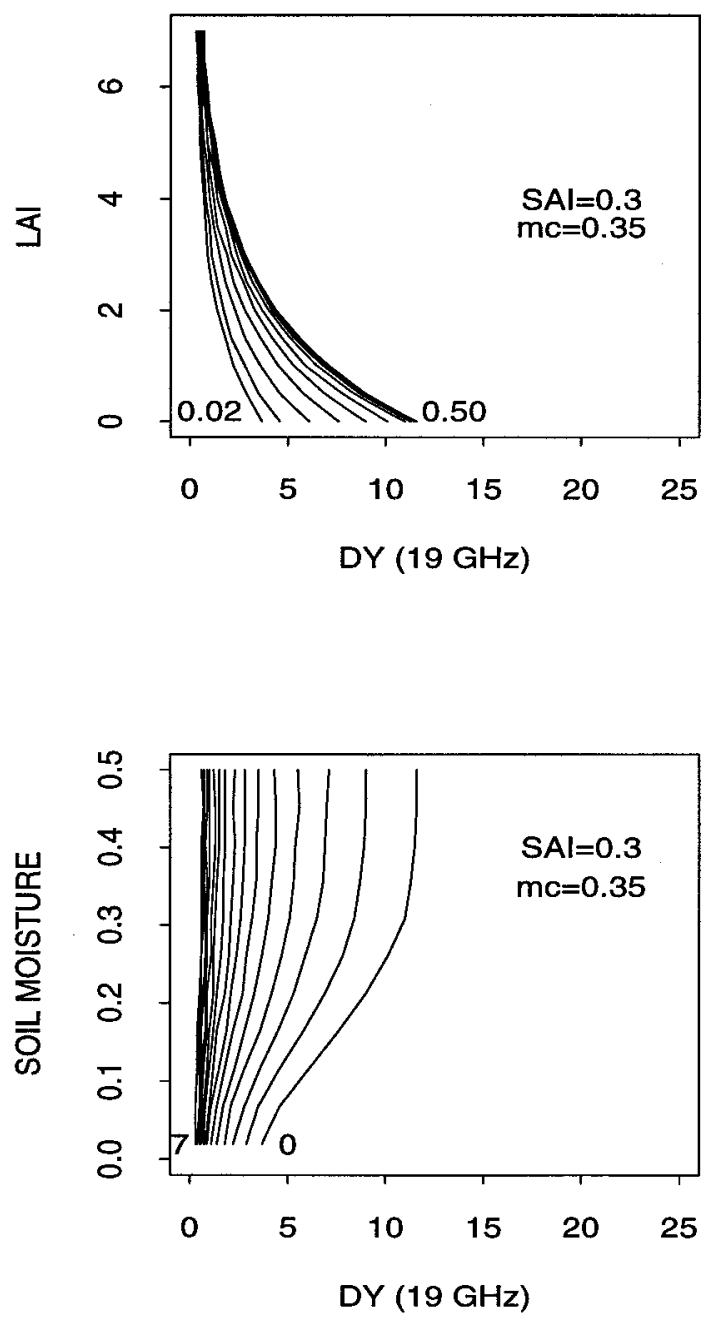

FIG. 7. Sensitivity of $19-\mathrm{GHz}$ polarization difference index (DY) to leaf area index for different soil moisture contents between 0.02 (residual) and 0.50 (saturation), and for volumetric soil moisture content for different leaf area indices between 0.0 and 7.0, for stem area index and canopy moisture content at 0.3 and 0.35 , respectively (from Lakshmi et al. 1996a).

1995, personal communication). Their algorithm is based on $\Delta T$ (for $37 \mathrm{GHz})>10 \mathrm{~K}$ for a melting snow layer. The $\Delta T$ for the $37-\mathrm{GHz}$ frequency on day 190 is $16.5 \mathrm{~K}$. (There is also a low value of the average brightness temperature $241.4 \mathrm{~K}$ and a high value of the SSM/ I-derived soil moisture 0.31 ). This indicates a possibility of melting snow. The corresponding $\Delta T$ for the same location and same day for the $19-\mathrm{GHz}$ frequency is 28.2 $\mathrm{K}, \bar{T}_{B}$ is $239.2 \mathrm{~K}$, and the SSM/I-derived soil moisture is 0.46 . The hourly air temperature records of the Surface Airways station closest to the above location in El Paso, Texas $\left(31.8^{\circ} \mathrm{N}, 106.4^{\circ} \mathrm{W}\right)$, shows a warming trend increasing up to $296 \mathrm{~K}$ at $1500 \mathrm{LT}$ on 3 February 1988. The air temperature continued to stay above $280 \mathrm{~K}$ for most of 4 February 1988 and at around $274 \mathrm{~K}$ on 5 February 1988. This may have caused the melting of
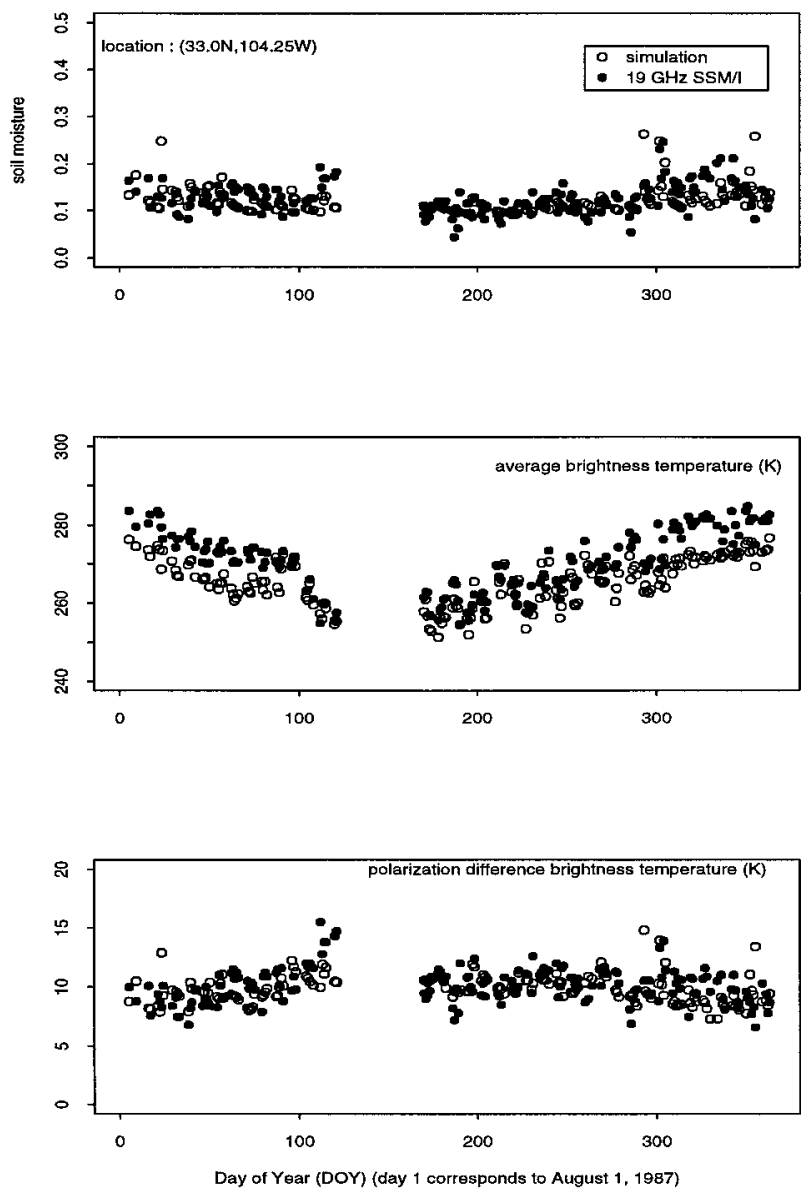

FIG. 8. Good agreement between the simulated and 19-GHz SSM/I brightness temperature-derived soil moisture and average and polarization difference brightness temperature at the location $33.0^{\circ} \mathrm{N}$ and $104.25^{\circ} \mathrm{W}$.

the snow accumulated on the ground surface at this location.

Examples of poor agreements between the simulated and the observation derived quantities are tabulated in Table 4 for 19 - and 37-GHz frequency. These correspond to the same location of $35.0^{\circ} \mathrm{N}, 95.75^{\circ} \mathrm{W}$. A good part of this $0.25^{\circ} \times 0.25^{\circ}$ pixel is occupied by the Eufaula Reservoir located on the Canadian River. The presence of a large water body in the pixel reduces the average brightness temperature and increases the polarization difference brightness temperature. A consequence of the increase in $\Delta T$ is large values (equal to saturation) of the SSM/I-derived soil moisture. The same is observed for a few other pixels of the SSM/I observations in the same area. There is a presence of water bodies in parts of the pixels that results in large root-mean-squared differences between the simulated and the observed soil moistures, and average and polarization difference brightness temperatures (see Table 4). The Eufaula Reservoir affects the first four pixels, and the Short Mountain Reservoir (located northeast of 

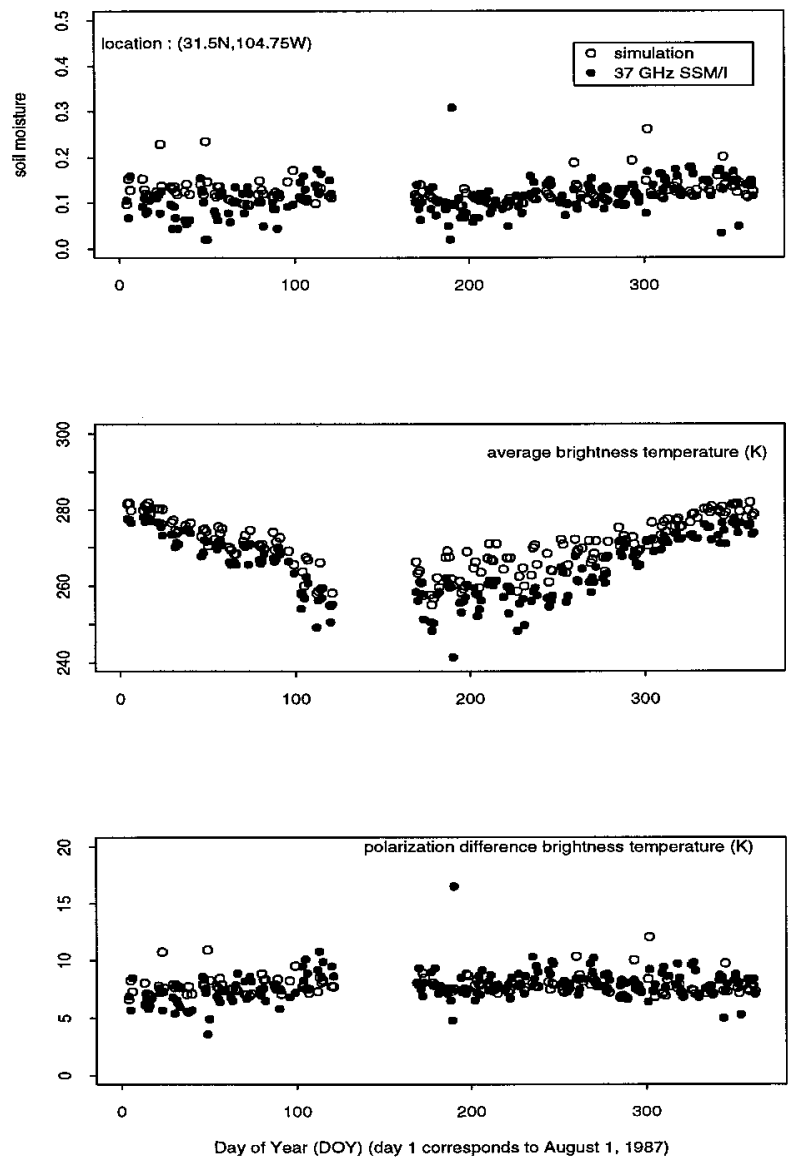

FIG. 9. Good agreement between the simulated and 37-GHz SSM/I brightness temperature-derived soil moisture and average and polarization difference brightness temperature at the location $31.5^{\circ} \mathrm{N}$ and $104.75^{\circ} \mathrm{W}$.

the Eufaula Reservoir, also on the Canadian River) affects the fifth pixel.

The sensitivity of the 19 - and the $37-\mathrm{GHz}$ channels to soil moisture in the presence of vegetation is almost identical. Therefore, for this paper and this study we did not focus on both of the channels. Ideally, one would expect a greater sensitivity of the $19-\mathrm{GHz}$ channel to soil moisture compared to the $37-\mathrm{GHz}$ channel. This is true, but the difference is small. The difference between the two soil moisture estimates is directly related to the difference in the sensitivity.

The confidence that can be placed on the soil moisture estimates can be ascertained by using the sensitivity relationship of the SSM/I polarization difference index to soil moisture as a function of LAI. Figure 7 shows that up to an LAI of 1.5 , there is sensitivity of the polarization difference index to soil moisture.

\section{c. SSM/I-derived monthly soil moisture estimates}

As seen in the previous sections the agreements between the SSM/I-estimated and the hydrologic model-
TABLE 4. Effect of water bodies on the SSM/I observations-rootmean-squared differences between simulated and observed brightness temperatures and simulated and estimated soil moisture for 19 and $37 \mathrm{GHz}$.

\begin{tabular}{lccccccc}
\hline \hline & \multicolumn{3}{c}{$19 \mathrm{GHz}$} & & \multicolumn{3}{c}{$37 \mathrm{GHz}$} \\
\cline { 2 - 3 } \cline { 7 - 9 } \multicolumn{1}{c}{ Location } & $\bar{T}_{B}$ & $\Delta T$ & $\theta$ & & $\bar{T}_{B}$ & $\Delta T$ & $\theta$ \\
\hline $35.25^{\circ} \mathrm{N}, 95.75^{\circ} \mathrm{W}$ & 0.30 & 6.9 & 4.7 & & 0.32 & 9.6 & 7.5 \\
$35.25^{\circ} \mathrm{N}, 96.0^{\circ} \mathrm{W}$ & 0.29 & 7.9 & 3.8 & & 0.29 & 5.7 & 4.0 \\
$35.5^{\circ} \mathrm{N}, 95.75^{\circ} \mathrm{W}$ & 0.24 & 7.3 & 3.2 & & 0.29 & 7.1 & 5.6 \\
$35.5^{\circ} \mathrm{N}, 96.0^{\circ} \mathrm{W}$ & 0.25 & 8.7 & 3.4 & & 0.25 & 5.8 & 3.8 \\
$35.5^{\circ} \mathrm{N}, 95.25^{\circ} \mathrm{W}$ & 0.21 & 7.3 & 2.8 & & 0.26 & 5.9 & 3.8 \\
\hline
\end{tabular}

simulated soil moistures were better for monthly averaging than for daily values. In the case of climate studies or studies involving global change, it is great importance to have a long-term soil moisture climatology. The present section uses monthly average soil moistures over the study region to understand and interpret the relationship between soil moisture, vegetation, and accumulated rainfall and to verify whether the soil moisture estimates created using the 19-GHz SSM/I brightness temperature data are consistent with our knowledge of these relationships. The monthly mean surface soil moisture created using the 19-GHz SSM/Iestimated soil moisture is shown in Fig. 10. This section interprets the mean monthly soil moisture derived from $\mathrm{SSM} / \mathrm{I} 19-\mathrm{GHz}$ data and relates it to the variations in the rainfall and LAI. The monthly mean soil moisture is greater in the eastern regions than in the western regions of the study area. This is especially true for January, February, and March 1988. This can be attributed to the greater rainfall in the east than in the west, as seen in Fig. 11. Figure 11 gives the monthly rainfall accumulations $(\mathrm{mm})$ for the study region. In the case of March 1988, the rainfall is greater in Fig. 11; however, the cases of January and February 1988 are not so clear, due to the scale of the rainfall images designed to span between the minimum and the maximum, which does not give an adequate grayscale variation for these months. For the months of February and March 1988, the rainfall is greater on the eastern edge than on the western edge of the study area. The eastern edge receives around $8-10 \mathrm{~mm}$ of rain in the northeastern corner and around $20-25 \mathrm{~mm}$ of rain in the southeastern corner in January 1988, and around $5-10 \mathrm{~mm}$ in the northeastern corner and $20-30 \mathrm{~mm}$ in the southeastern corner in February 1988. The western edge receives 0$5 \mathrm{~mm}$ in January 1988 and February 1988. Since, in these months, the evaporation from the soil is low, the rainfall is reflected in the increased surface soil moisture, and the greater soil moisture in the eastern edge compared to the western edge can be attributed to greater rainfall. For the months of April through July 1988, the mean monthly soil moisture tends to follow the rainfall pattern and the pattern of the LAI. The mean monthly LAI is shown in Fig. 12. The increase in the LAI in the eastern region of the study area results in an increase 

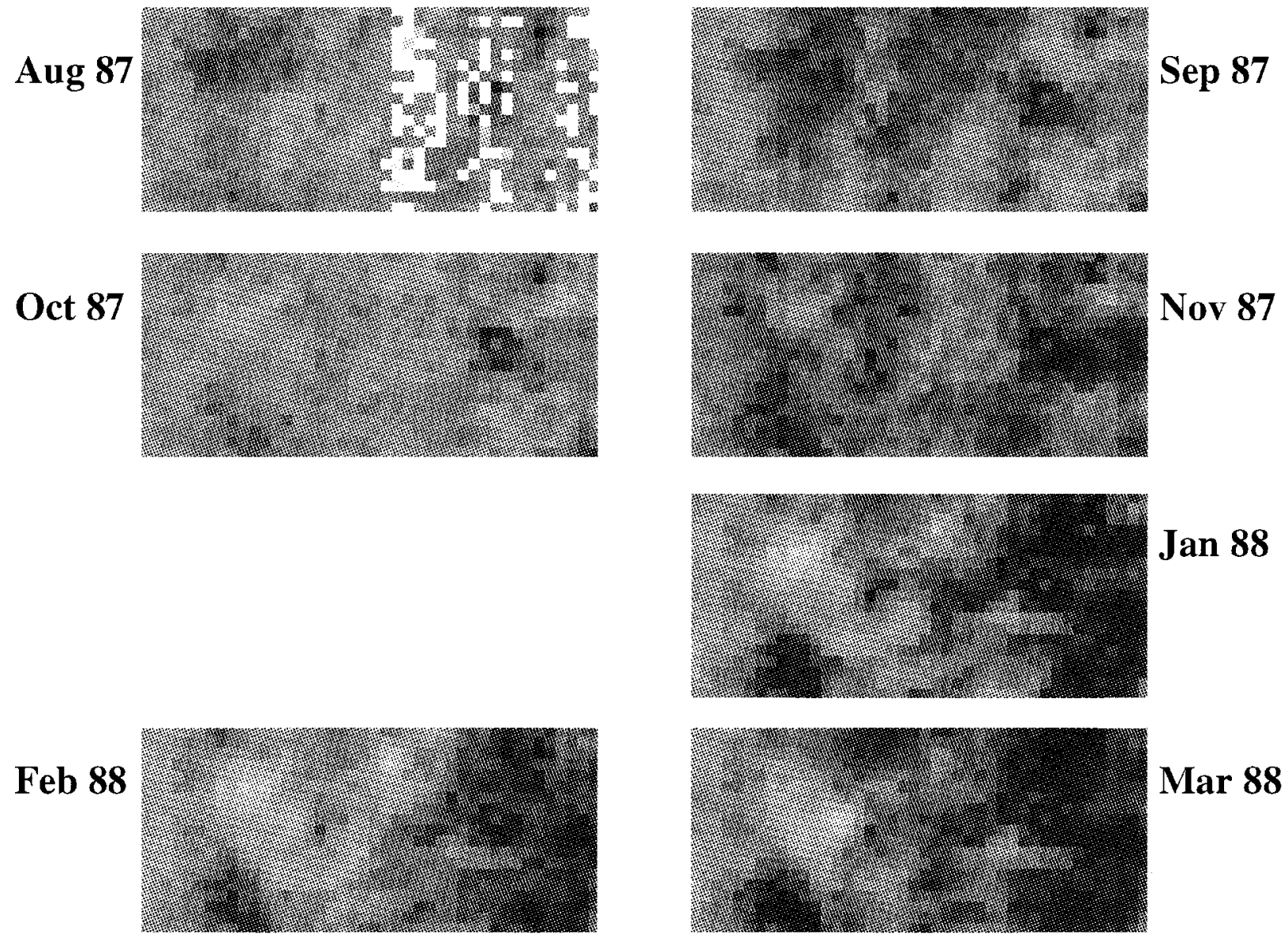

Mar 88
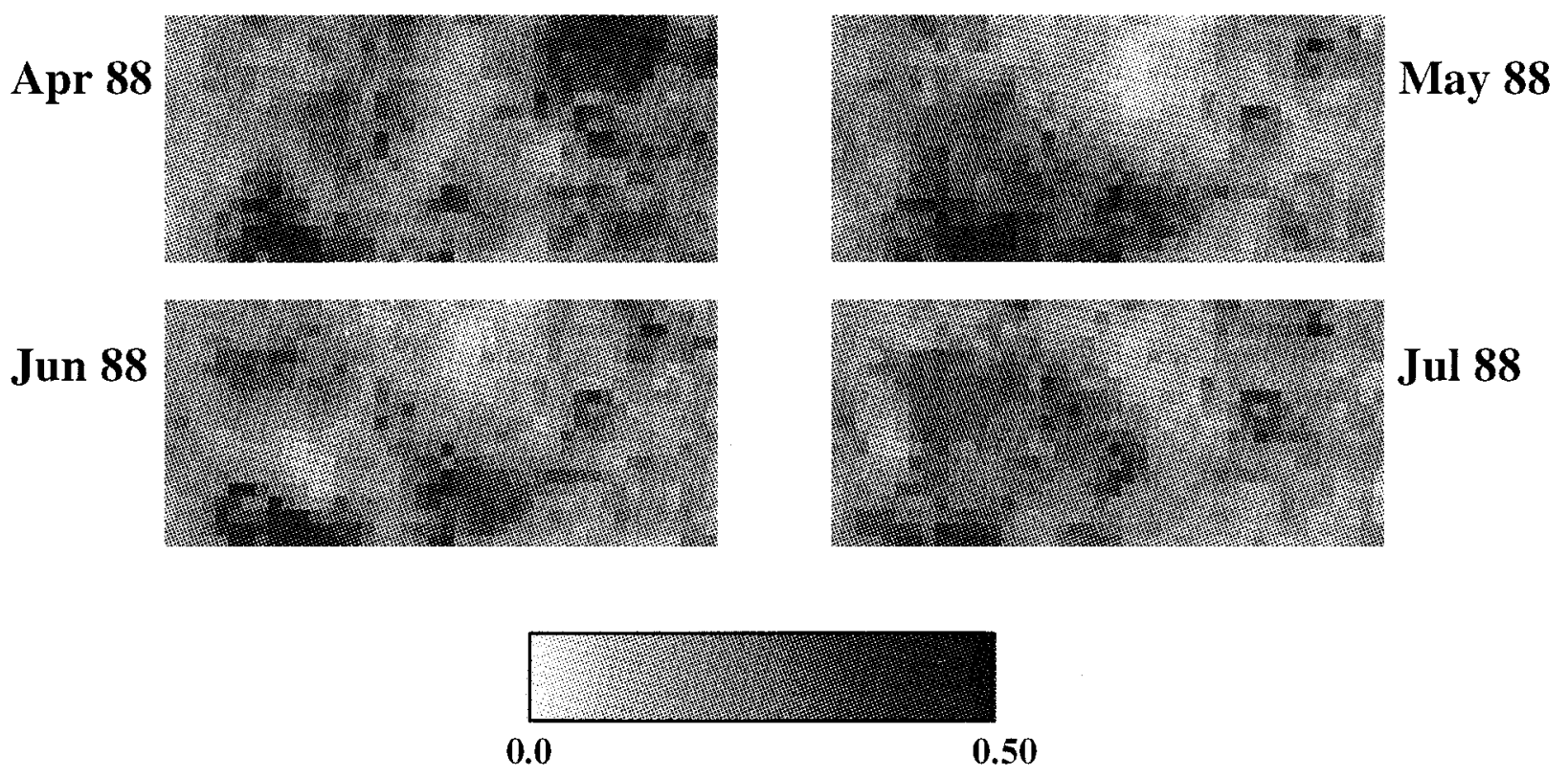

FIG. 10. Mean monthly $0.25^{\circ} \times 0.25^{\circ}$ soil moisture derived from 19-GHz SSM/I data between August 1987 and July 1988. The SSM/I was turned off in December 1987. 


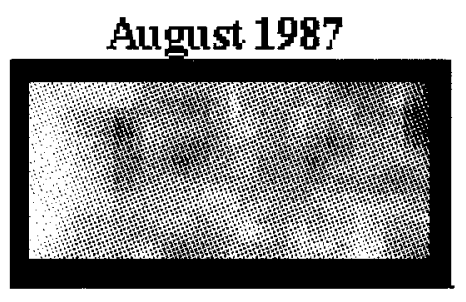

October 1987

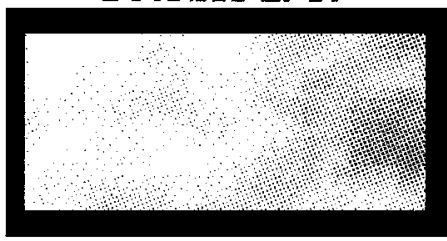

Dexember 1987

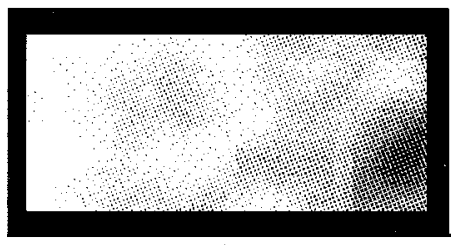

February 1988

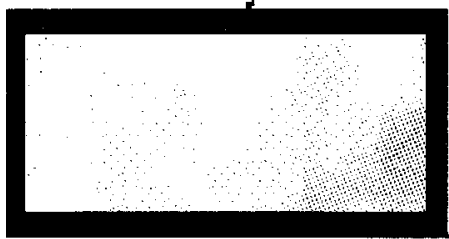

Aprii 1988

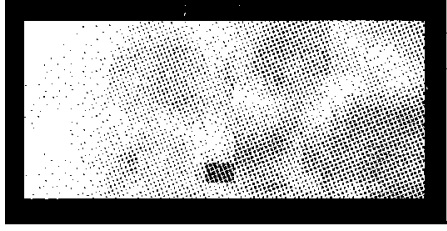

June 1988

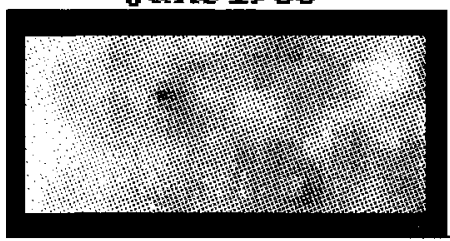

Sep tember 1987

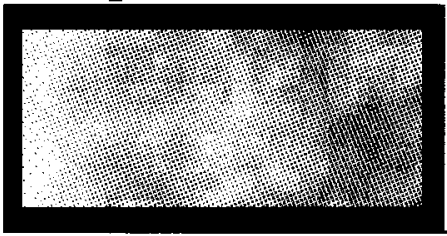

November 1987

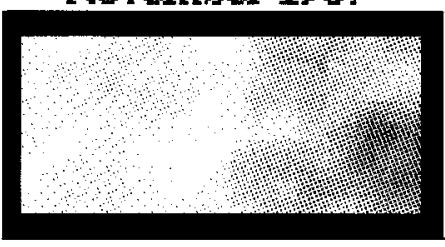

Jamuary 1988

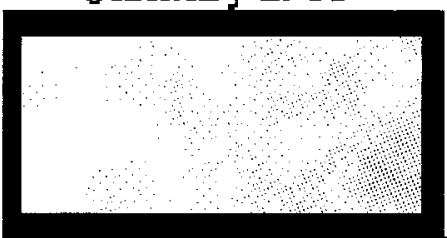

March 1988

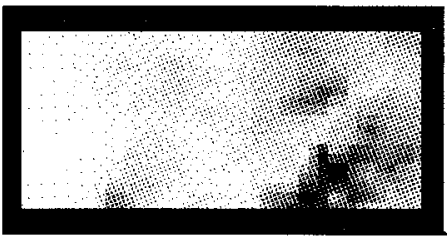

May 1988

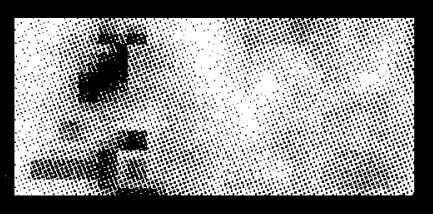

July 1988

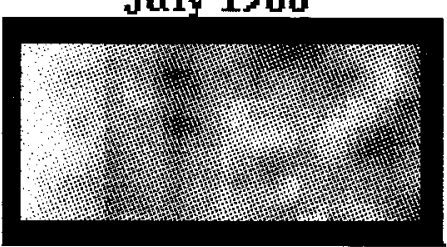

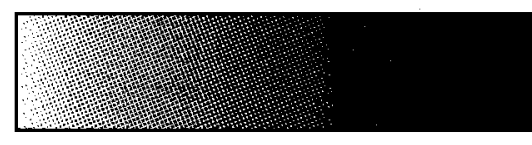

0

$500 \mathrm{~mm}$

Fig. 11. Cumulative monthly $0.25^{\circ} \times 0.25^{\circ}$ precipitation $(\mathrm{mm})$ between August 1987 and July 1988 
August 1987

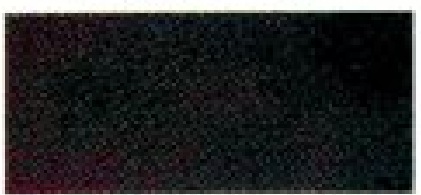

October 1987

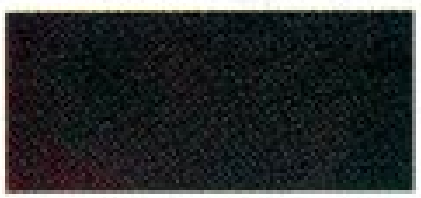

December 1987

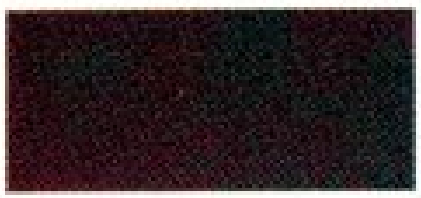

February 1988

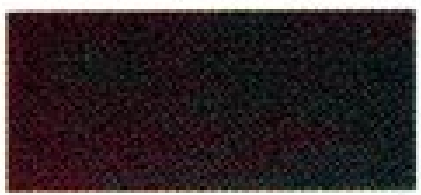

April 1988

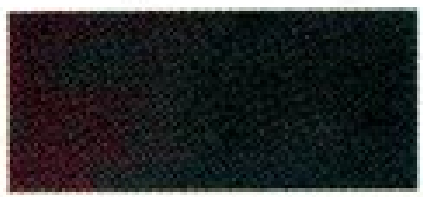

June 1988

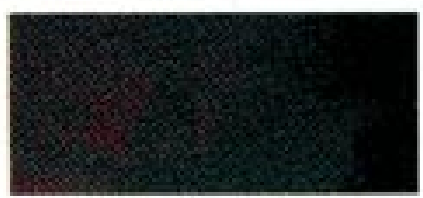

September 1987

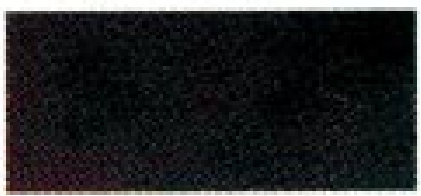

November 1987

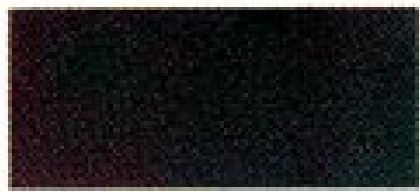

Jamuary 1988

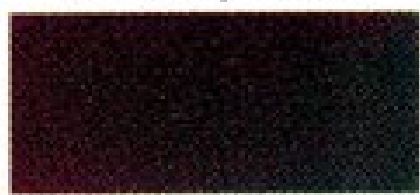

March 1988

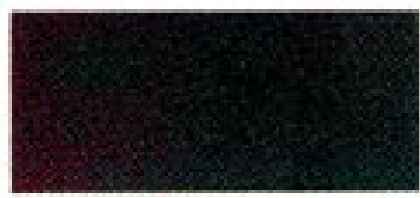

May 1988

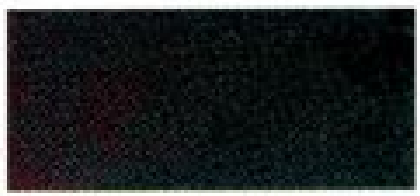

July 1988

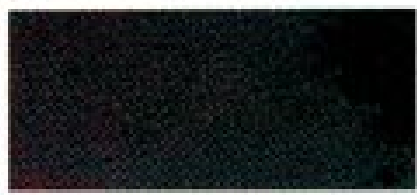

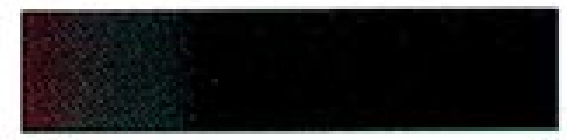

0.0

2.5

FIG. 12. Mean monthly $0.25^{\circ} \times 0.25^{\circ}$ leaf area index between August 1987 and July 1988 . 
in evapotranspiration losses, and surface soil moistures are consequently not as high as they were in the first 3 months of 1988. Also, the rainfall distribution is not biased as much toward higher values in the east as in January through March 1988. The higher values of rainfall in the west and central regions, together with lower LAI values (than for the eastern region), result in values of soil moisture that are higher than those of the first 3 months of 1988 and that are comparable to those of the eastern region during these three months. Examination of Fig. 10 clearly shows greater uniformity of soil moisture in the months of April through July 1988. The soil moisture of August through November 1987 can be explained in a similar fashion. The area of high soil moisture in the east-central area in November 1988 corresponds to a higher rainfall accumulation. The variation of mean monthly soil moisture across the study area can be viewed as an integrated reflection of the monthly accumulated rainfall and LAI patterns. The above study shows that the mean monthly soil moistures constructed using the $19-\mathrm{GHz}$ brightness temperature data are consistent with what is expected from the variations of the accumulated rainfall and LAI.

\section{d. SSM/I-derived monthly evaporation estimates}

The evapotranspiration derived using SSM/I data was compared with the estimates from an atmospheric model. The atmospheric water budget is written as (Abdulla et al. 1996)

$$
\frac{\partial W}{\partial t}+\boldsymbol{\nabla} \cdot \mathbf{Q}=E-P
$$

where $W$ is the precipitable water in the atmospheric column computed using radiosonde data, $E$ is the evapotranspiration estimated as a residual, $P$ is the precipitation, and $\boldsymbol{\nabla} \cdot \mathbf{Q}$ is the divergence of moisture flux. The water vapor flux $Q$ is computed as

$$
Q=\int_{300 \mathrm{mb}}^{P_{s}} q U \frac{d p}{g},
$$

where $q$ is the specific humidity, $U$ is the horizontal wind velocity, $g$ is the acceleration due to gravity, and $p$ is the pressure. The limits of integration $p_{s}$ correspond to surface pressure, and $300 \mathrm{mb}$ corresponds to a level sufficiently high enough in the atmospheric column above which there is insignificant water vapor present.

The atmospheric budget computations were carried out over a box extending between $32^{\circ}$ and $40^{\circ} \mathrm{N}$ and $92^{\circ}$ and $108^{\circ} \mathrm{W}$. This box is bigger than the present study area. This is reasonable since the values of convergence derived using a smaller area will be based on a lesser number of radiosonde data sources, and these estimates of water vapor convergence may not be reliable. In addition, the atmospheric budget computations are carried out over a 16-yr period extending between 1973 and 1989. This time period includes the time period of the

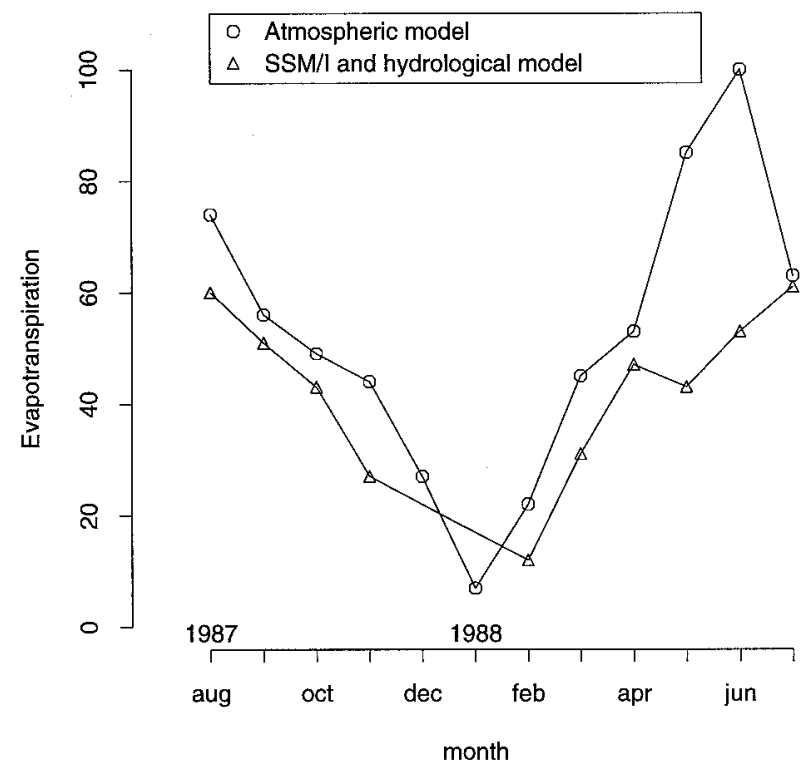

FIG. 13. Monthly total evapotranspiration computed using atmospheric water vapor budgets and estimated using SSM/I and hydrologic modeling.

present simulation study (1 August 1987-31 July 1988). Therefore, the estimates derived from this atmospheric budget analysis do hold relevance for the present study area and time period. However, the variations between the actual atmospheric budget estimates for August 1987-July 1988 and this 16-yr average may be slight, considering that the averages are over a 16-yr period and that they include variations and sample all of the variations during 1987-88. Therefore, the results of the atmospheric budget analysis in the form of mean monthly evapotranspiration estimates have been adopted for comparison with the SSM/I-estimated evapotranspiration.

The water vapor convergence values were used to derive the evapotranspiration estimate (Abdulla et al. 1996) over the box using observed precipitation values and the radiosonde data interpolated onto $1^{\circ}$ grids $(\mathrm{Ab}$ dulla et al. 1996). The mean monthly values of the evapotranspiration estimates are presented in Fig. 13.

The evapotranspiration is estimated using the SSM/ I-derived surface soil moisture and the thin-layer hydrologic model-derived water fluxes using Eq. (1); that is,

$$
E T=P-R-q_{2}-Q_{b}-z_{1} \frac{d \theta}{d t}-z_{2} \frac{d \theta_{2}}{d t},
$$

where $P$ is the cumulative monthly precipitation; $R, q_{2}$, and $Q_{b}$ are the cumulative monthly surface runoff, drainage from the lower layer, and base flow from the lower layer computed using the hydrologic model, respectively, $d \theta_{1} / d t$ is the monthly change in the upper-layer storage estimated from the SSM/I-derived soil moisture; $d \theta_{2} / d t$ is the change in the lower soil moisture storage 
derived from the hydrologic model estimates; and $z_{1}$ and $z_{2}$ are the thicknesses of the upper and lower layers, respectively.

The monthly variation of the cumulative evapotranspiration is shown in Fig. 13. The evapotranspiration totals estimated using the SSM/I soil moisture and the hydrologic model show good agreement with the atmospheric water vapor budget estimates. There is, however, a consistent underestimation of the atmospheric model-derived evapotranspiration by the SSM/I and the hydrologic model-estimated values. The magnitude of underestimation is low for August, September, and October 1987 (14, 5, and $6 \mathrm{~mm}$, respectively). There is no estimation from the SSM/I or the hydrologic model for the months of December 1987 and January 1988 since the SSM/I was not functional between December 1987 and 12 January 1998. The underestimation is larger in 1988, with $10 \mathrm{~mm}$ in February and $14 \mathrm{~mm}$ in March, decreasing to $6 \mathrm{~mm}$ in April 1988. The underestimation is large for May and June (42 $\mathrm{mm}$ and $47 \mathrm{~mm}$ ) and shows good agreement for July 1988, with an underestimation of only $2 \mathrm{~mm}$. The SSM/I- and hydrologic model-derived evapotranspiration totals show the proper seasonal variation, with a maximum of $60 \mathrm{~mm}$ in August 1987 and July 1988 and a minimum of $12 \mathrm{~mm}$ in February 1988 . The monthly variations of the two evapotranspiration estimates follow the same trend, with the exception of a decrease in evapotranspiration from June $(100 \mathrm{~mm})$ to July $(63 \mathrm{~mm})$ in the case of the atmospheric budget estimates and an increase in the evapotranspiration from $53 \mathrm{~mm}$ (June 1988) to $61 \mathrm{~mm}$ (July 1988) according to the SSM/I and hydrologic model estimates. The evapotranspiration shows a decrease between $\mathrm{Au}-$ gust and January, and an increase until July. These results demonstrate the potential of the SSM/I, in conjunction with a hydrologic model, to give good estimates of regional evapotranspiration.

\section{e. Comparison of results with previous studies}

The correlation coefficients and the root-meansquared differences are computed between the simulated and the SSM/I-estimated values for soil moistures, and the average and polarization difference temperatures for 19 and $37 \mathrm{GHz}$. There is an important point to be made here. There is no connection (except for calibration) between the SSM/I-estimated values of soil moisture and the simulated values. The two sets of soil moisture values (simulated and SSM/I estimated) are derived independently of each other. The correlation coefficients and the root-mean-squared differences interpreted in this perspective show modest correlations and rootmean-squared differences that are not high.

The correlation coefficient between the estimated antecedent precipitation index (API) using 6.6-GHz SMMR brightness temperature data (Choudhury and Golus 1988) and the simulated API is 0.87 . Their correlations are higher because (a) the lower frequency (6.6
$\mathrm{GHz}$ in their case) is much more sensitive to soil wetness and (b) a longer span (5 yr-1979-83) of data for a selected period in the year (Julian days 121-243) was used. The 19-GHz data used by Teng et al. (1993) have lower $r$ between the simulated and estimated API than in the previous study of Choudhury and Golus (1988). The $0.25^{\circ} \times 0.25^{\circ} \mathrm{SSM} / \mathrm{I}$ data in their study have been averaged to $0.75^{\circ} \times 0.75^{\circ}$ pixels. The correlation coefficients have been reported for yearly averaged values and for two distinct regions (the semiarid western part and the humid eastern part). The correlation coefficient is lower for the eastern part than for the western part. Since the study by Teng et al. (1993) uses the 19- and 37-GHz SSM/I observations used in this investigation, it is worthwhile to compare their $r$ (between calculated and $19-\mathrm{GHz}$ SSM/I-estimated API) and the $r$ (between simulated and 19-GHz SSM/I-derived soil moistures) from this study. The values for the coefficient of correlation between the $19-\mathrm{GHz}$ SSM/I-estimated API and the calculated API for different geographic locations ranged between a maximum of 0.7 in the semiarid western region and a minimum of 0.35 for the humid central part of western Iowa and western Missouri for 1987. The corresponding values for 1988 were 0.7 and 0.45 . In this study, the average correlation coefficient between the SSM/I-estimated soil moisture and the simulated soil moisture (computed from daily correlation values between 1 August 1987 and 31 July 1988) is 0.131 for 19 $\mathrm{GHz}$ and 0.128 for $37 \mathrm{GHz}$. The lower values could be attributed to the stricter procedures adopted in this study for simulating and estimating the soil moisture. The soil moisture has been simulated using a complete water and energy balance model, and the estimation has been carried out using a physically based radiative transfer model. In the study of Teng et al. (1993), the API method was used, which is an approximation for soil moisture, and the estimation was done through regression analysis. The regression relations between the horizontally polarized $19-\mathrm{GHz}$ brightness temperatures and the API are different for the arid western region and the humid eastern region. The present study is more physically based, and it analyzes the physically based relationships between the SSM/I-observed brightness temperatures and the soil moisture, rainfall, and vegetation. The average correlation coefficient between the simulated and the estimated soil moisture, computed on a weekly averaged basis, is 0.255 and 0.247 for the 19 - and $37-\mathrm{GHz}$ frequencies, respectively, and on a monthly basis is 0.379 and 0.378 for 19 and $37 \mathrm{GHz}$, respectively. Again, it can be seen that averaging helps increase the agreement between the two sets of soil moisture.

Note that the coefficient of correlation gives us an idea of the agreement between the two independent estimates of soil moisture. In reality, the two could differ depending upon the errors in the hydrologic model and its inputs, in the SSM/I sensor, and in the estimation procedure. Future work will use the knowledge of these 
errors in assimilating the soil moistures into the hydrologic model using the results of the present work.

\section{Conclusions and implications for future work}

The coupled soil-canopy-atmosphere model has been used to simulate soil moisture and brightness temperatures for a region in the Red River basin of the southern United States. The 19- and $37-\mathrm{GHz}$ simulations and comparisons with observed values were carried out on a $0.25^{\circ} \times 0.25^{\circ}$ grid for a period of $1 \mathrm{yr}$ between 1 August 1987 and 31 July 1988. The simulated brightness temperatures at 19 and $37 \mathrm{GHz}$ were compared against the SSM/I-observed brightness temperatures. The rootmean-squared difference between the simulated and the observed average and the polarization difference brightness temperatures decreases as the comparison period for which the averaging is done is increased-that is, the monthly average brightness temperatures show a lower root-mean-squared difference than the weekly values, and the weekly values exhibit a lower error than the daily values. The simulated surface temperatures were compared with the observed surface temperatures derived from air temperature measurements. These results showed that the root-mean-squared error of the surface temperature at the time of the SSM/I overpass ranged between 1 and $4 \mathrm{~K}$. The comparisons between the simulated and the $19-\mathrm{GHz} \mathrm{SSM} / \mathrm{I}-$ estimated soil moistures show reasonable correlations. The range of the correlation coefficient increases as the time period of averaging for the soil moisture comparison decreases. The monthly average estimates of surface soil moisture derived from the SSM/I are interpreted in context with the monthly rainfall and the monthly averaged LAI. The SSM/I-derived monthly average surface soil moisture shows a very strong relationship with the cumulative monthly rainfall. The root-mean-squared differences between the SSM/I-derived and the hydrologic model estimates of soil moisture depend on the amount of vegetation. Higher values of LAI in the growing season mask the soil moisture signal and result in larger rootmean-squared differences. The cumulative monthly estimates of evapotranspiration computed using the SSM/I estimates of soil moisture in conjunction with the hydrologic model yielded good comparisons with the monthly estimates obtained via the atmospheric budget analysis.

The study described in this paper can be extended in time and space to achieve better understanding of more diverse situations. Extension of this study to a time period of $5 \mathrm{yr}$ would help to explain some of the interannual variations observed by the SSM/I. This is very relevant in the discussions of SSM/I monthly climatology for the calculation of the mean monthly SSM/Iestimated soil moisture and the cumulative monthly evapotranspiration computed using the SSM/I and the hydrologic model. Extension of this analysis to a larger area (the Mississippi River basin or the Red-Arkansas
River basin) would definitely help to interpret the results in the context of varying geographic regions. The use of SSM/I data in conjunction with AVHRR NDVI data can help to monitor crop development and detect early stages of drought (Teng et al. 1995). Studies have shown that vegetation indexes like NDVI are good indicators of the onset of drought (Tucker 1989). The use of surface soil moisture information estimated using SSM/I in conjunction with the NDVI estimates from AVHRR may provide a better indicator of the vegetation information. The spatial resolutions of the SSM/I at 19 and $37 \mathrm{GHz}$ are about 56 and $33 \mathrm{~km}$, respectively. It is very difficult to plan field experiments at such large scales. However, if homogeneous areas (with respect to vegetation type) are chosen and a field experiment carried out to measure soil moisture, a valuable dataset will be provided with which the results of modeling and the estimation of soil moisture can be compared. Field experiments on large scales, such as the SSM/I resolution scale, will help bridge the gap that exists between small-scale field experiments and large-scale modeling.

We lack field observations of soil moisture over large scales. This makes it very difficult to quantify the errors in simulation and estimation. We therefore did the next best thing-made comparisons of SSM/I estimations and hydrologic simulations. This does not mean that the hydrologic simulations are the truth. It is our hope that large-scale field experiments will help us to create databases for the future and that SSM/I data can be used to estimate soil moisture, as well as the errors in estimation. These estimates can be used in a data-assimilation mode, which is one of our goals for land surface modeling efforts in the Earth Observing System context.

The importance of large-scale datasets of soil moisture cannot be emphasized enough. In situ field observations are expensive and may not be representative of the actual variations. The use of satellite microwave brightness temperatures will help us in the estimation of soil moistures and will, in conjunction with a hydrologic model, provide measures of evapotranspiration. These quantities (soil moisture and evapotranspiration) are useful for large-scale water and energy balances studies.

\section{REFERENCES}

Abdulla, F. A., D. P. Lettenmaier, E. F. Wood, and J. A. Smith, 1997: Application of a macroscale model to estimate the water balance for the Arkansas-Red River basin. J. Geophys. Res., in press.

Alihouse, J. C., S. A. Snyder, J. Vongsathorn, and R. R. Ferraro, 1990a: Determination of oceanic total precipitable water from the SSM/I. IEEE Trans. Geosci. Remote Sens., 28, 811-816.

—, J. B. Snider, E. R. Westwater, C. T. Swift, C. S. Ruf, S. A. Synder, J. Vongsathorn, and R. R. Ferraro, 1990b: Determination of cloud liquid water content using SSM/I. IEEE Trans. Geosci. Remote Sens., 28, 817-822.

Baeck, M. L., and J. A. Smith, 1997: Climatological analysis of manually digitized radar data for the United States east of the Rocky Mountains. Water Resour. Res., in press.

Baret, F., and G. Guyot, 1991: Potentials and limits of vegetation 
indices for LAI and APAR assessment. Remote Sens. Environ., 35, 161-173.

Bradley, A. A., and J. A. Smith, 1993: Extremes for precipitable water and stability indices during the warm season. Preprints, 13th Conf. on Weather Analysis and Forecasting Including Symp. on Flash Floods, Vienna, VA, Amer. Meteor. Soc., 3.63.7.

Chandrashekar, S., 1960: Radiative Transfer. Dover, 393 pp.

Choudhury, B. J., 1993: Reflectivities of selected land surface types at 19 and $37 \mathrm{GHz}$ from SSM/I observations. Remote Sens. Environ., 46, 1-17.

—_, and B. J. Blanchard, 1983: Simulating soil water recession coefficients for agricultural watersheds. Water Res. Bull., 17, 767-774.

— , and C. J. Tucker, 1987: Monitoring global vegetation using Nimbus-7 $37 \mathrm{GHz}$ data, some empirical relations. Int. J. Remote Sens., 8 (7), 1837-1868.

— data. Int. J. Remote Sens., 9, 1251-1257.

—, J. R. Wang, A. Y. Hsu, and Y. L. Chien, 1990: Simulated and observed $37 \mathrm{GHz}$ over Africa. Int. J. Remote Sens., 11, 18371868.

Dozier, J., and J. Frew, 1990: Rapid calculation of terrain parameters for radiation modeling from digital elevation data. IEEE Trans. Geosci. Remote Sens., 28, 963-969.

Eagleson, P. S., 1970: Dynamic Hydrology. McGraw Hill, 462 pp.

Fan, Y., E. F. Wood, M. L. Baeck, and J. A. Smith, 1996: Fractional coverage of rainfall over a grid: Analyses of NEXRAD data over the southern plains. Water Resour. Res., 32, 2787-2802.

Goodberlet, M. A, C. T. Swift, and J. C. Wilkerson, 1990: Ocean surface wind-speed measurements of the Special Sensor Microwave Imager (SSM/I). IEEE Trans. Geosci. Remote Sens., 28, 823-828.

Goward, S. N., S. Turner, D. G. Dye, and S. Liang, 1994: The University of Maryland Improved Global Vegetation Index Product. Int. J. Remote Sens., 15, 3365-3395.

Heymsfield, G. M., and R. Fulton, 1992: Modulation of SSM/I microwave soil radiances by rainfall. Remote Sens. Environ., 39, 187-202.

Hollinger, J. P., J. L. Peirce, and G. A. Poe, 1990: SSM/I instrument evaluation. IEEE Trans. Geosci. Remote Sens., 28, 781-790.

Idso, S. B., 1981: A set of equations for full spectrum and 8-14 $\mu \mathrm{m}$ and $10.5-12.5 \mu \mathrm{m}$ thermal radiation from cloudless skies. Water Resour. Res., 17, 295-304.

Lakshmi, V., 1995: Use of Special Sensor Microwave Imager data for soil moisture estimation. Ph.D. thesis, Princeton University, 225 pp. [Available from Princeton University, Princeton, NJ 08544.]

— E. E. Wood, and B. J. Choudhury, 1997a: A soil-canopy-atmosphere model for use in satellite microwave remote sensing. J. Geophys. Res., 102 (D6), 6911-6927.

,-- , and $-1997 \mathrm{~b}$ : Investigation of effect of heterogeneities in vegetation and rainfall on simulated SSM/I brightness temperatures. Int. J. Remote Sens., in press.

Lanicci, J. M., T. N. Carlson, and T. T. Warner, 1987: Sensitivity of the Great Plains severe storm environment to soil moisture distribution. Mon. Wea. Rev., 115, 2660-2673.

Mahfouf, J. F., E. Richard, and P. Mascart, 1987: The influence of soil and vegetation on mesoscale circulations. J. Climate Appl. Meteor., 26, 1483-1495.

Mahrt, L., and H. Pan, 1984: A two-layer model of soil hydrology. Bound.-Layer Meteor., 29, 1-20.

McFarland, M. J., R. L. Miller, and C. M. U. Neale, 1990: Land surface-temperature derived from the SSM/I passive microwave brightness temperatures. IEEE Trans. Geosci. Remote Sens., 28, 839-845.

Mintz, Y., 1984: The sensitivity of numerically simulated climates to land surface conditions. The Global Climate, J. Houghton, Ed., Cambridge University Press, 79-105.

Moore, P. L., and D. L. Smith, 1979: Manually digitized radar dataInterpretation and application. NOAA Tech. Memo. NWS SR-99, National Weather Service, Silver Spring, MD.

Nagler, T., and H. Rott, 1992: Development and intercomparisons of snow mapping algorithms based on SSM/I data. Proc. IGARSS 1992, 812-814.

Owe, M., A. A. van de Griend, and A. T. C. Chang, 1992: Surface soil moisture and satellite microwave observations in semi-arid southern Africa. Water Resour. Res., 28, 829-839.

Prabhakara, C., G. Dalu, G. L. Liberti, J. J. Nucciarone, and R. Suhasini, 1992a: Rainfall estimation over oceans from SMMR and SSM/I microwave data. J. Appl. Meteor., 31, 532-552.

,--1, R. Suhasini, J. J. Nucciarone, and G. L. Liberti, 1992b: Rainfall over oceans-Remote-sensing from satellite microwave radiometers. Meteor. Atmos. Phys., 47, 177-199.

Rawls, W. J., D. L. Brakensiek, and K. E. Saxton, 1982: Estimation of soil water properties. Trans. Amer. Soc. Agric. Eng., 25, 1316 1320.

Rind, D., 1982: The influence of ground moisture conditions in North America on summer climate as modeled in the GISS GCM. Mon. Wea. Rev., 110, 1487-1494.

Rowntree, P. R., and J. R. Bolton, 1983: Simulation of atmospheric response to soil moisture anomalies over Europe. Quart. J. Roy. Meteor. Soc., 109, 501-526.

Schluessel, P., and W. J. Emery, 1990: Atmospheric water-vapor over oceans from SSM/I measurements. Int. J. Remote Sens., 11, $753-$ 766.

Schmugge, T., 1985: Remote sensing of soil moisture. Hydrological Forecasting, M. G. Anderson and T. P. Burt, Eds., John Wiley, 101-124.

Shukla, J., and Y. Mintz, 1982: Influence of land surface evapotranspiration on earth's climate. Science, 215, 1498-1500.

Steffen, K., and A. J. Schweiger, 1990: A multisensor approach to sea ice classification for the validation of DMSP-SSM/I passive microwave derived sea ice products. Photogramm. Eng. Remote Sens., 56, 75-82.

Stephens, G. L., 1988: Radiative transfer through arbitrarily shaped optical media. Part I: A general method of solution. J. Atmos. Sci., 45, 1818-1836.

Teng, W. L., J. R. Wang, and P. C. Doraiswamy, 1993: Relationship between satellite microwave radiometric data, antecedent precipitation index, and regional soil moisture. Int. J. Remote Sens., 14, 2483-2500.

, P. C. Doraiswamy, and J. R. Wang, 1995: Temporal variations of the microwave polarization difference index and its relationship to the normalized difference vegetation index in a densely cropped area. Photogramm. Eng. Remote Sens., 61, 1033-1040.

Tennessee Valley Authority, 1972: Heat and mass transfer between a water surface and the atmosphere. Laboratory Rep. 14.

Townshend, J. R. G., 1989: Comparison of passive microwave with near-infrared and visible data for terrestrial environment monitoring. Int. J. Remote Sens., 10, 1633-1642.

Tucker, C. J., 1989: Comparing SMMR and AVHRR for drought monitoring. Int. J. Remote Sens., 10 (10), 1663-1672.

Ulaby, F. T., R. K. Moore, and A. K. Fung, 1981: Microwave Remote Sensing. Vol. 1. Addison-Wesley, $456 \mathrm{pp}$.

$\longrightarrow$, - and - 1986: Microwave Remote Sensing: Active and Passive. Vol. 3, From Theory to Applications, Artech, 2162 pp.

Walker, J. M., and P. R. Rowntree, 1977: The effect of soil moisture on circulation and rainfall in a tropical model. Quart. J. Roy. Meteor. Soc., 103, 29-46.

Yeh, T. C., R. T. Weatherald, and S. Manabe, 1984: The effect of soil moisture on short-term climate and hydrology change-A numerical experiment. Mon. Wea. Rev., 112, 474-490.

Zhang, D. L., and R. A. Anthes, 1982: A high-resolution model of the planetary boundary layer-Sensitivity tests and comparisons with SESAME-79 data. J. Appl. Meteor., 21, 1594-1609. 